\title{
An Internal Atmospheric Process Determining Summertime Arctic Sea Ice Melting in the Next Three Decades: Lessons Learned from Five Large Ensembles and Multiple CMIP5 Climate Simulations
}

\author{
DÁniel Topál, ${ }^{\mathrm{a}, \mathrm{b}}$ QinghuA Ding, ${ }^{\mathrm{b}}$ JONATHAN MitChell, ${ }^{\mathrm{c}, \mathrm{d}}$ IAN BAXTER, ${ }^{\mathrm{b}}$ MÁTYÁs Herein, ${ }^{\mathrm{e}, \mathrm{f}}$ \\ TÍMEA HASZPRA, ${ }^{\mathrm{e}, \mathrm{f}}$ RUI LUO, ${ }^{\mathrm{b}, \mathrm{h}}$ AND QINGQUAN LI ${ }^{\mathrm{g}}$ \\ ${ }^{a}$ Institute for Geological and Geochemical Research, Research Centre for Astronomy and Earth Sciences, Budapest, Hungary \\ ${ }^{b}$ Department of Geography, Earth Research Institute, University of California, Santa Barbara, Santa Barbara, California \\ ${ }^{c}$ Department of Atmospheric and Oceanic Sciences, University of California, Los Angeles, California \\ ${ }^{d}$ Department of Earth, Planetary and Space Sciences, University of California, Los Angeles, California \\ ${ }^{e}$ Institute for Theoretical Physics, Eötvös Loránd University, Budapest, Hungary \\ ${ }^{f}$ MTA-ELTE Theoretical Physics Research Group, Eötvös Loránd University, Budapest, Hungary \\ ${ }^{g}$ Laboratory for Climate Studies, National Climate Center, China Meteorological Administration, Beijing, China \\ ${ }^{h}$ Department of Atmospheric and Oceanic Sciences and Institute of Atmospheric Sciences, Fudan University, \\ Shanghai, China
}

(Manuscript received 23 October 2019, in final form 10 June 2020)

\begin{abstract}
Arctic sea ice melting processes in summer due to internal atmospheric variability have recently received considerable attention. A regional barotropic atmospheric process over Greenland and the Arctic Ocean in summer (June-August), featuring either a year-to-year change or a low-frequency trend toward geopotential height rise, has been identified as an essential contributor to September sea ice loss, in both observations and the CESM1 Large Ensemble (CESM-LE) of simulations. This local melting is further found to be sensitive to remote sea surface temperature (SST) variability in the east-central tropical Pacific Ocean. Here, we utilize five available large "initial condition" Earth system model ensembles and 31 CMIP5 models' preindustrial control simulations to show that the same atmospheric process, resembling the observed one and the one found in the CESM-LE, also dominates internal sea ice variability in summer on interannual to interdecadal time scales in preindustrial, historical, and future scenarios, regardless of the modeling environment. However, all models exhibit limitations in replicating the magnitude of the observed local atmosphere-sea ice coupling and its sensitivity to remote tropical SST variability in the past four decades. These biases call for caution in the interpretation of existing models' simulations and fresh thinking about models' credibility in simulating interactions of sea ice variability with the Arctic and global climate systems. Further efforts toward identifying the causes of these model limitations may provide implications for alleviating the biases and improving interannual- and decadal-time-scale sea ice prediction and future sea ice projection.
\end{abstract}

\section{Introduction}

The recent dramatic reduction in summer [June-August (JJA)] Arctic sea ice cover has become an iconic symbol of climate change (Vaughan et al. 2013). The scientific community has reached broad consensus that the observed sea ice decline is mostly attributable to anthropogenic forcing and its associated positive feedbacks, collectively known as Arctic amplification (Deser et al. 2010; Cohen et al. 2014; Screen and Simmonds 2010; Simmonds 2015; Notz and Stroeve 2016; Screen et al. 2018; Jahn 2018). In addition, it is well known that internal variability has played an important

Corresponding author: Qinghua Ding, qinghua@ucsb.edu role in regulating sea ice decadal variability in the past (Day et al. 2012; Zhang 2015; Notz and Marotzke 2012; England et al. 2019). However, the relative contribution of internal variability to the total sea ice change and how models simulate the melting process due to internal variability are still unclear, which hinders us from making a more reliable projection of Arctic sea ice melting in the upcoming decades.

Internal drivers of sea ice variability have been suggested to originate from both oceanic (Zhang 2007; Tokinaga et al. 2017) and atmospheric processes (Lee 2012; Notz 2014; Swart et al. 2015; Grunseich and Wang 2016; Ding et al. 2017; Wernli and Papritz 2018; Olonscheck et al. 2019; Labe et al. 2019). Previous research successfully linked observed Arctic summer 
circulation anomalies-featuring either a year-to-year change or a low-frequency trend toward regional geopotential height rise above Greenland and the Arctic Ocean-to September sea ice variability over the past four decades and drew attention to the importance of a local Arctic internal atmospheric process driving sea ice variability (Ding et al. 2017, 2019). This circulation pattern resembles a barotropic anticyclone favoring a circulation-driven tropospheric warming and moistening and manifests as the primary mechanism of the local atmosphere-sea ice coupling (Ding et al. 2017, 2019). Analysis by Ding et al. (2019) using the fully coupled CESM1 Large Ensemble (CESM-LE) simulations alone attributes $40 \%-50 \%$ of the observed summer sea ice melting since 1979 to this internal atmospheric process, which is also suggested by Hahn et al. (2018) to be in connection with the recent rapid Greenland ice sheet melt. Additionally, the Atlantic multidecadal oscillation and the Pacific decadal oscillation were both suggested to be major internal drivers of Arctic surface temperature and sea ice variability via their related ocean and atmosphere heat transport on multidecadal/centennial time scales (Chylek et al. 2009; Zhang 2015; Screen and Francis 2016; Castruccio et al. 2019).

Besides these two prominent extratropical sea surface temperature (SST) modes, which are believed to be important due to their proximity to the Arctic, more recent studies have revealed that internal SST variability residing in the tropical Pacific can also have substantial impact on Arctic climate (Ding et al. 2014; Baxter et al. 2019; Screen and Deser 2019). Meehl et al. (2018), using an atmosphere-only model, suggested that summer sea ice variability is more sensitive to SST anomalies in the tropical Atlantic in line with a more recent study that emphasized the importance of an atmospheric bridge connecting the tropical Atlantic and Pacific (McCrystall et al. 2020). In addition, Baxter et al. (2019) showed observational and modeling evidence that a Rossby wave train, induced by a cold SST anomaly in the eastcentral tropical Pacific, can propagate into the Arctic and manifest as an anomalous high pressure over the Arctic Ocean. This high pressure plays a key role to physically link September sea ice variability with tropical SST changes (Baxter et al. 2019; Ding et al. 2017, 2019).

Nonetheless, remote drivers of Arctic sea ice variability are still controversial. Svendsen et al. (2018) imputed an important role for Pacific decadal variability in driving the early-twentieth-century warming and proposed that the current transitioning of the interdecadal Pacific oscillation (IPO) from cooling to a warming phase can lead to an accelerated Arctic warming. Consistently, Screen and Deser (2019) also attribute an important role for Pacific Ocean variability in the timing of a seasonally ice-free Arctic in the CESM-LE simulations. However, Ding et al. (2019) and Baxter et al. (2019) both note that the summer IPO-Arctic linkage in the CESM-LE is different from that in observations. Observations reveal an out-of-phase relationship between tropical and Arctic surface temperature trends: negative tropical SST changes are associated with positive Arctic surface temperature changes. Nevertheless, CESM-LE historical simulations feature an opposite trend: positive tropical SST trends fall in line with positive Arctic surface temperature trends. In addition, Blanchard-Wrigglesworth and Ding (2019) recently realized that summertime tropical-Arctic linkages are quite weak in the CESM-LE. The complex nature of how lower latitude processes may influence Arctic climate change is further exemplified by atmosphere-only model relaxation experiments (Ye and Jung 2019) along with Dong et al. (2019) who highlighted how important the differences in the relative contribution of regional specific Pacific surface warming in global feedback changes are. Furthermore, Bonan and Blanchard-Wrigglesworth (2020) recently proposed that the relatively short observational record may hinder us from fully understanding the stationarity of tropical-Arctic linkages.

All these emphasize existing nontrivialities of tropicalArctic teleconnections and that tropical forcing on Arctic climate simulated in the CESM-LE should be treated cautiously. More large ensemble simulations are needed to evaluate the common features and performance in simulating tropical-Arctic linkages across all available models in the community and whether models share a similar atmosphere-driven process governing Arctic sea ice variability as revealed in observations and the CESMLE (Ding et al. 2017, 2019). Recently, six additional large ensembles (from five independent modeling centers) have become available and four of them provide necessary variables for an analysis of the atmosphere-sea ice coupling, which provides a new opportunity to achieve our goal. However, a total of five large ensembles (including the CESM-LE) are still not enough to represent the full spectrum of models' performance in simulating sea ice response to the atmosphere. To increase models' diversity in this study, we use a complementary way to explore models' internal variability through a pseudoensemble method (Rosenblum and Eisenman 2017; Ding et al. 2019) focusing on the preindustrial control simulations from CMIP5. By comparing the five large ensembles with 31 long (longer than 200 years of integration) control simulations from CMIP5, we aim to search for common features of local and remote atmospheric drivers of internal sea ice variability in the preindustrial, historical, and future simulations in multiple warming scenarios as well as to assess the ability of 
current climate models to capture observed features of these local and remote drivers.

Since the atmosphere-sea ice interactions may share some similar coupling mechanisms on year-to-year and low-frequency time scales in observations (Ding et al. 2017, 2019), we focus our model analysis on both year-to-year (using correlation analyses in section 4a) and low-frequency (using a linear trend-based method in sections $4 \mathrm{~b}-\mathrm{d}$ ) time scales when studying the atmosphere-sea ice coupling. Our study, therefore, provides a chance to gain a deeper insight into physical mechanisms behind both the recent sea ice loss and year-to-year variability in summer. Through our analysis, we also aim to advance our understanding of tropical-Arctic linkages and their possibly decisive role in determining the interannual and decadal prediction of summertime Arctic sea ice.

\section{Data and methods}

\section{a. Reanalysis, SST, and sea ice data}

We use monthly geopotential height $Z$ and temperature $T$ data at 27 pressure levels and the surface temperature (TS) variable from the European Centre for Medium-Range Weather Forecasts interim reanalysis (ERA-Interim, hereinafter ERA-I) (Dee et al. 2011). Despite uncertainties between different reanalysis datasets, Ding et al. (2017) showed that ERA-I well reproduces the radiosonde measurements in and around the Arctic, therefore we compare our model results with ERA-I. SST data are obtained from ERSSTV5 (Huang et al. 2017). Sea ice data are derived from the National Snow and Ice Data Center (NSIDC) climate data record of passive microwave sea ice concentration (SIC), version 3, of the NSIDC (Cavalieri et al. 1996). We calculate sea ice area (SIA) as the product of ice concentration and grid element area in each sea ice grid. Then the total September sea ice area index (SIA index) is constructed as the sum of sea ice area in all Arctic grid cells where ice concentration is greater than $15 \%$. Given the sensitivity of sea ice's annual minimum to climate variability in the Arctic, we focus on the September total sea ice area index from observations and each of the model simulations.

\section{b. Time frame}

We target our historical analysis at the 1979-2012 period when the strongest September sea ice melting is observed along with remarkable JJA geopotential height rise above northeastern Canada and Greenland (Ding et al. 2014, 2017, 2019; Mioduszewski et al. 2016). After 2012 the Arctic circulation shows a pattern with less prominent height rise and a slowdown in September sea ice melting (Swart et al. 2015; Baxter et al. 2019). Results, however, appear to be insensitive to the chosen time window. Our future analysis, involving the RCP2.6, RCP4.5, and RCP8.5 scenarios (Taylor et al. 2012), is focused on the next three decades until 2050, when the models show the strongest sea ice melting (Fig. 1).

\section{c. Model experiments: Five large ensembles, preindustrial, and historical simulations in CMIP5}

Internal variability is an inherent feature of the climate system. When creating single-model large ensemble simulations, unlike the CMIP5 ensemble, the same model is run several times with small perturbations in the initial condition, thus the single runs-that share the model physics and the external forcing-are considered parallel realizations of the same model. In this way internal variability and the forced component are separable within a certain model, which is an advantage over using multimodel simulations when exploring internal processes in the climate system (Drótos et al. 2015). Here we utilize five currently available "initial condition" large ensembles (LE) of fully coupled Earth System Models collected by the U.S. CLIVAR Large Ensembles working group (Deser et al. 2020) including (i) the Max Planck Institute 100-member Grand Ensemble (MPI-GE; Maher et al. 2019), (ii) the CanESM2 50member LE (CanESM-LE) (Kirchmeier-Young et al. 2017), (iii) the 40-member CESM-LE (Kay et al. 2015), (iv) the CSIRO Mk3.6 30-member LE (Jeffrey et al. 2013), and (v) the GFDL CM3 20-member LE (GFDL-LE) (Sun et al. 2018). We use model output for 1979-2080 with CMIP5 historical forcing (Taylor et al. 2012) until 2005 and RCP8.5 forcing for 2006-80. Additionally, we use the other two available RCP2.6 and RCP4.5 forcing scenarios from MPI-GE for 2006-80, which allows us to examine interactions between internal climate variability and anthropogenic forcing with different intensity. In addition, we utilize historical + RCP8.5 (1979-2080) simulations of 31 climate models from CMIP5 and preindustrial simulations of the same group of CMIP5 models (Table 1). These preindustrial runs contain integrations longer than 200 years representing a realization of one individual model. The reason we include these runs in our study is to assess whether the bias in Arctic teleconnections from the five large ensembles are common across all available models in CMIP5. To reduce uncertainty arising from the different model physics, we will primarily focus on the mean of four of the five large ensembles (excluding CSIRO-LE; for details see section 3) and the mean of 31 preindustrial simulations and before averaging all model outputs are regridded onto the ERA-I $1.5^{\circ}$ regular grid applying the ERA-I land-sea mask.

\section{d. Statistical significance and MCA}

We use the Student's $t$ test to calculate significance of both correlations and composite values. Linear trends of 


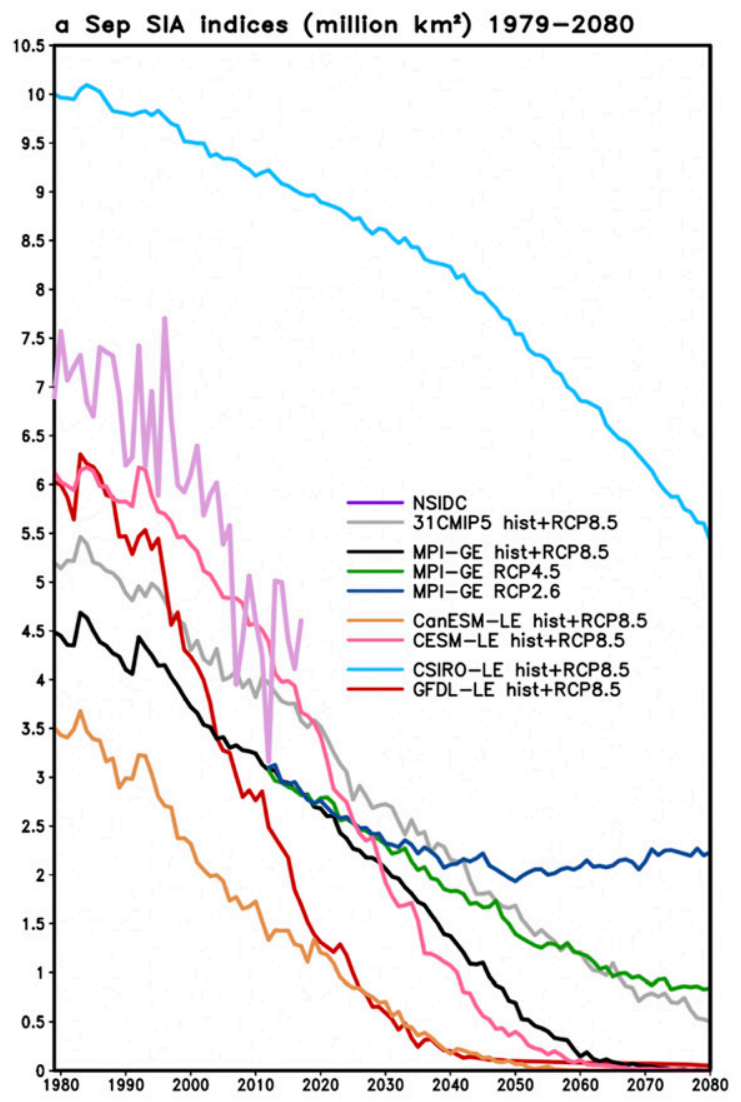

b MPI-GE

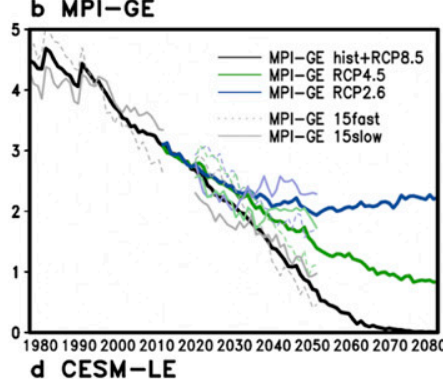

d CESM-LE

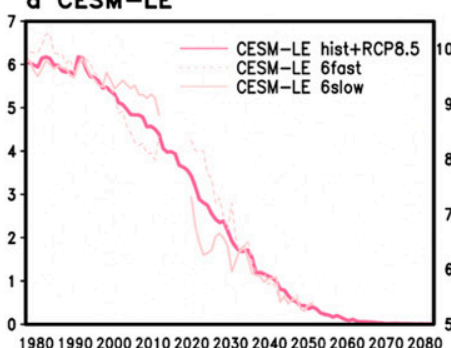

198019902000201020

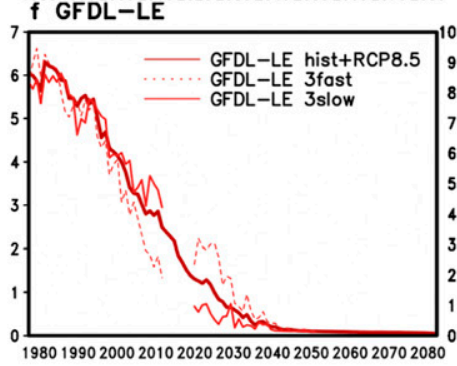

c CanESM-LE

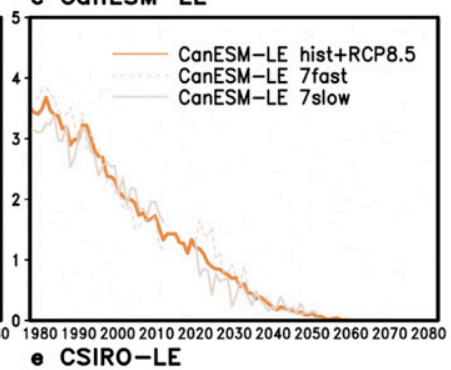

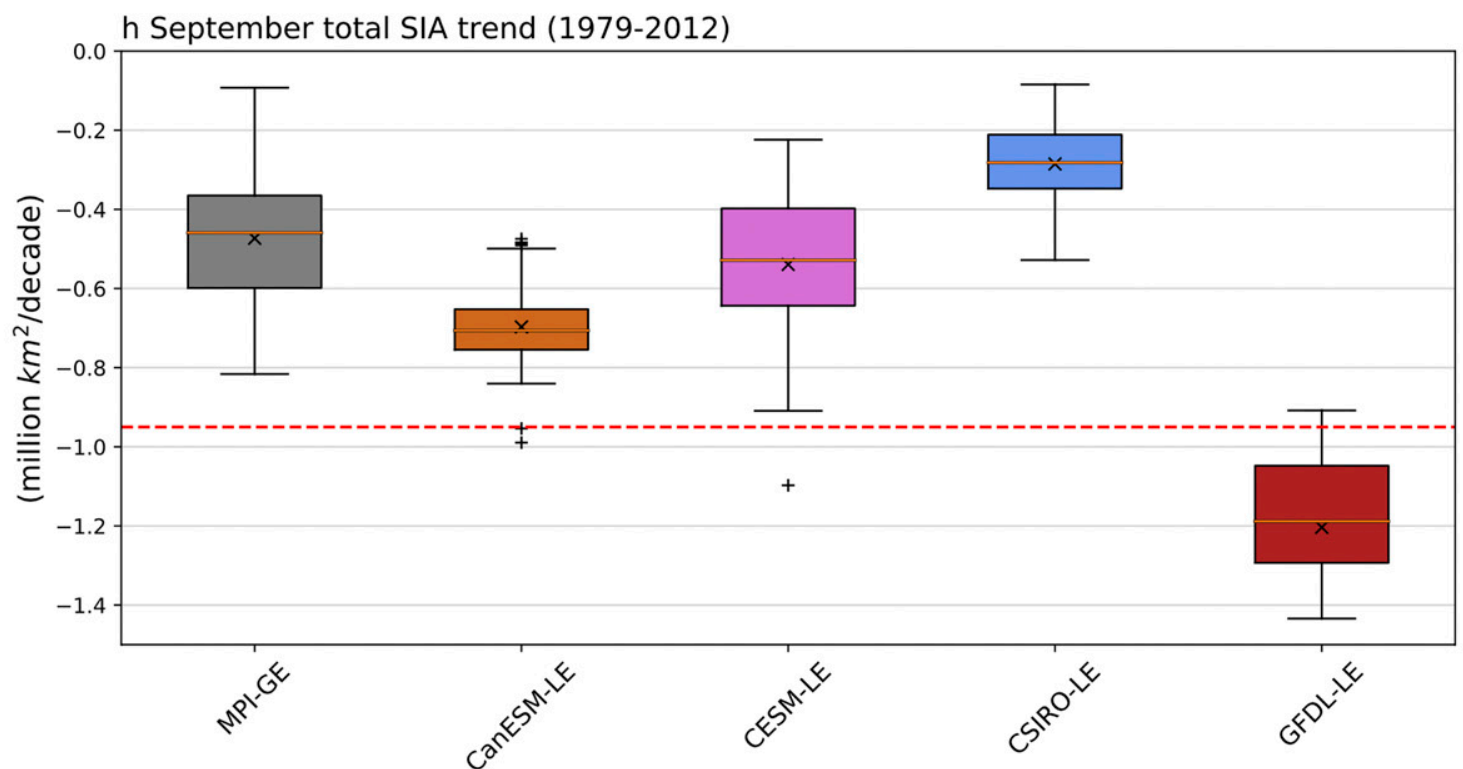

FIG. 1. (a) Time evolution of the observed (1979-2017) (purple), the multimodel ensemble mean of CMIP5 models (gray), and the forced model component of five LE simulations (single-model LE historical + RCP8.5 ensemble mean) September SIA indices (19792080) as indicated on the legend $\left(10^{6} \mathrm{~km}^{2}\right)$. Also shown is the time evolution of the ensemble mean (thick solid line) and the slow (thin solid line) and fast (dashed line) groups (based on 15\% of the total ensemble members) for (b) MPI-GE, (c) CanESM-LE, (d) CESM-LE, (e) CSIRO-LE, and (f) GFDL-LE, along with (g) 31 CMIP5 model SIA indices (thin gray lines) and the multimodel ensemble mean (thick gray line). (h) Box-and-whiskers plot of September total SIA linear trends (1979-2012) in the five LE simulations (indicated below the $x$ axis) and the observed trend (red dashed line: $-0.95 \times 10^{6} \mathrm{~km}^{2}$ decade ${ }^{-1}$ ). The whiskers extend to $1.5 \times$ IQR. Crosses mark average values; plus signs mark the outliers (outside $1.5 \times \mathrm{IQR}$ ). The median is indicated with an orange horizontal line. 
TABLE 1. The 31 climate models in the CMIP5 historical + RCP8.5 and preindustrial control experiments that were used in the study, and the length of the preindustrial (PI) run. Expansions/ definitions of the models are available online (https://www.ametsoc.org/ PubsAcronymList).

\begin{tabular}{lc}
\hline \multicolumn{1}{c}{ CMIP5 model name } & Length of PI run (yr) \\
\hline 1. ACCESS1.0 & 500 \\
2. ACCESS1.3 & 500 \\
3. CanESM2 & 996 \\
4. CMCC-CESM & 277 \\
5. CMCC-CM & 330 \\
6. CMCC-CMS & 500 \\
7. CNRM-CM52 & 490 \\
8. CNRM-CM5 & 850 \\
9. CSIRO Mk3.6.0 & 500 \\
10. GFDL CM3 & 500 \\
11. GFDL-ESM2G & 500 \\
12. GFDL-ESM2M & 500 \\
13. GISS-E2-H & 251 \\
14. GISS-E2-H-CC & 780 \\
15. GISS-E2-R & 251 \\
16. GISS-E2-R-CC & 1062 \\
17. HadGEM2-CC & 240 \\
18. HadGEM2-ES & 314 \\
19. INM-CM4 & 500 \\
20. IPSL-CM5A-LR & 1000 \\
21. IPSL-CM5B-LR & 300 \\
22. IPSL-CM5A-MR & 300 \\
23. MIROC-ESM & 870 \\
24. MIROC-ESM-CHEM & 255 \\
25. MIROC5 & 630 \\
26. MPI-ESM-LR & 1000 \\
27. MPI-ESM-MR & 1000 \\
28. MPI-ESM-P & 1156 \\
29. MRI-CGCM3 & 500 \\
30. NorESM1-M & 252 \\
31. NorESM1-ME & 501 \\
\hline & \\
& \\
\hline
\end{tabular}

time series are removed each time before calculating correlations. Maximum covariance analysis (MCA) — which uses singular value decomposition of the covariance matrix to search for optimally coupled patterns between the two input fields (Bretherton et al. 1992) - is applied to explore the covariability between Arctic sea ice and atmospheric circulation.

\section{e. Fast-minus-slow composite: A simple but efficient way to distinguish internal from forced variability}

Teasing apart internal variability of any observed and simulated variable from its forced component is challenging. Here, making use of the state-of-the-art large ensemble simulations, we implement a simple method to separate atmospheric processes originating from internal climate variability from those resulting from the models' forced component, which is regarded as the cumulative effects of anthropogenic plus natural external forcing. Because we are especially interested in searching for an internal atmospheric process acting as a driver upon summer sea ice melting as described in Ding et al. (2019), we focus on the spread of September total SIA index variable between the members of the ensemble that lets us separate groups of members showing fast and slow melting for a given time period (based on linear trends). Having identified those members of the fast- and slow-melting groups we average the corresponding linear trends in JJA, for example, 200-hPa geopotential height Z200, in each group and calculate the difference between the two Z200 composites (divided by two, so as to scale to the ensemble mean). We do the same with zonal mean geopotential height $Z$, zonal mean temperature $T$, surface temperature TS and September SIA. We will refer to the difference of the fast and slow group Z200, Z, T, TS, and SIA trends as the fast-minus-slow Z200, Z, T, TS, and SIA composites, respectively. Because all ensemble members are forced in the same way, the fast-minus-slow composites remove the forced signal and retain signals that originate from fundamental internal atmospheric variability. Since correlation between sea ice and a given atmospheric variable, assuming linearity, reflects the strength of the coupling between them, we can compare the composite trend patterns to the results obtained from the correlation analysis to determine whether a similar pattern is present over the two time scales. The selection of the number of ensemble members belonging to the fast and slow groups is based on choosing $\sim 15 \%$ (approximately 1 standard deviation from the mean) of the total number of ensemble members (members in each group: MPIGE: 15, CanESM-LE: 7, CESM-LE: 6, CSIRO-LE: 5, and GFDL-LE: 3 members).

To account for possible limitations of the fast-minusslow composite, we further explore how well the fastand slow-melting groups represent the total ensemble spread of the simulated atmosphere-sea ice coupling. In doing so, first, we calculate linear trends in all members of a given LE over 1979-2012 for both JJA Z200 and September SIC within the Arctic (north of $60^{\circ} \mathrm{N}$ ). Second, we remove the ensemble mean trend from each member, so the residual trends of each member only reflect inherent internal variability of a model over the selected time period. To understand how sea ice and Z200 are coupled in the Arctic due to pure internal variability, we calculate MCA (Bretherton et al. 1992; Li et al. 2017) between JJA Z200 and September SIC trend fields across all the members in a given LE. In this way, the time expansion coefficients will not reflect temporal changes, rather member series, which we compare with the magnitude of September total SIA index linear trend derived from each member. The comparison reveals that the fast and slow melting groups (based on 1 
standard deviation of linear trends in September total SIA index) show the strongest negative and positive loading in the intermember MCA. Thus, we are confident that the fast-minus-slow composite can basically capture the leading mode of covariability between Z200 and sea ice for 1979-2012 as well as for the future (202050) time frame as the repeated analysis confirmed.

\section{f. Pseudoensemble of preindustrial CMIP5 simulations}

Additionally, we extend the fast-minus-slow method to 31 CMIP5 models that have at least 200-yr-long preindustrial control simulations. Cutting the $200+$-yr-long control runs into consecutive 34 -yr periods we create a pseudoensemble with $n-33$ members, where $n$ is the length of the given CMIP5 model's control run (Rosenblum and Eisenman 2017; Ding et al. 2019) and each member corresponds to a 34-yr-long time series. Although the pseudoensemble members are not initialized with perturbations in the initial condition and the consecutive members have overlapping periods-therefore, strictly speaking, they do not represent the full scope of possible climate states allowed by internal variability-the control runs have constant external forcing thus the members of the pseudoensemble are assumed to be generated by the given model's purely internal climate physics (or model specific biases as is the case with single-model LEs as well). We then search for the 34-yr-long periods showing the fastest and slowest sea ice melting based on linear trends and difference the corresponding Z200, Z, T, TS, SIA trends to construct the fast-minus-slow composite. Similar to the real-ensemble calculations we select $15 \%$ of the total number of the pseudoensemble members for each of the fast and slow groups. Averaging these 31 fast-minus-slow composite patterns we provide an overview of CMIP5 model performance in capturing the observed coupling of sea ice with both the local Arctic and remote tropical atmosphere on low-frequency time scales.

\section{September sea ice changes in the historical and future warming scenarios}

Figure 1 gives an overview of the time evolution of the September total SIA index in observations and model simulations for 1979-2080, in addition to the linear trends in each model ensemble members compared to the observed melting rate over the historical era (19792012; Fig. 1h). Figure 1a shows the historical + RCP8.5 ensemble mean simulations of each large ensemble's September total SIA indices (solid colored lines) and the ensemble mean of 31 CMIP5 runs (solid gray line) along with the NSIDC observations (solid purple line). The observed prominent rate of melting and interdecadal variability are not well captured in any of the singlemodel or the CMIP5 multimodel ensemble mean simulations (Fig. 1a; Baxter et al. 2019). This indicates a possible role for internal variability in driving sea ice variability in the past and very likely in the upcoming decades too. Furthermore, the large decline seen in the observed record between 1979 and 2012 lies outside the $1.5 \times$ interquartile range (IQR) of four LE simulations' spread, except for the GFDL-LE, which shows extensive melting (Fig. 1h). Sources for this underestimation may be rooted in a lower sea ice sensitivity (Rosenblum and Eisenman 2017; Notz and Stroeve 2016) of most current climate models or other processes inherent to the climate dynamics, part of which is the subject of the present study.

Except for the CSIRO-LE, each of the ensemble simulations underestimate SIA on the historical time frame relative to observations with the CESM-LE resembling the observed SIA magnitude the best (Fig. 1a). The CMIP5 ensemble mean relatively well represents the average of the other LEs' sea ice conditions on the historical time frame; however, after the early 2010s, four of five LE experiments (except for the CSIRO-LE) start to melt sea ice considerably faster than the CMIP5 mean. On the historical time frame, of the five model ensembles, the GFDL-LE and the CanESM-LE melt sea ice the fastest with ice-free conditions $\left(<10^{6} \mathrm{~km}^{2}\right)$ in the near future, and the MPI-GE (Notz et al. 2013) and the CSIRO-LE mean simulations show the slowest rate of ice melt on both the historical and future time windows (Fig. 1a). The rate of summer sea ice melt in the CESM-LE accelerates after 2012 picturing a seasonally ice-free Arctic Ocean in the model within the next three decades (Screen and Deser 2019). The colored thin dashed (thin solid) lines in Figs. 1b-f represent the fast (slow) sea ice melting groups in each of the model ensembles. These are the members' average September total SIA index time series that were selected to construct the fast-minus-slow composites. Note, that for all the five model ensembles the members of the fast group initially contain more ice than those of the slow group, which seems natural, since, by construction, the fast group has to start with more ice so that it has more ice to melt (Figs. 1b-f).

Note also that the magnitude of the ensemble mean of the CSIRO-LE SIA simulations considerably stands out from the other simulations, indicating that a realistic summer mean sea ice state may be missing in the model (Uotila et al. 2013), which makes the comparison with observed summer sea ice conditions questionable. The lack of a correctly replicated summer mean state might also affect other current climate models, which are potential targets of future large ensemble simulations: the large spread in the simulated total September SIA 
a NSIDC 1979-2012

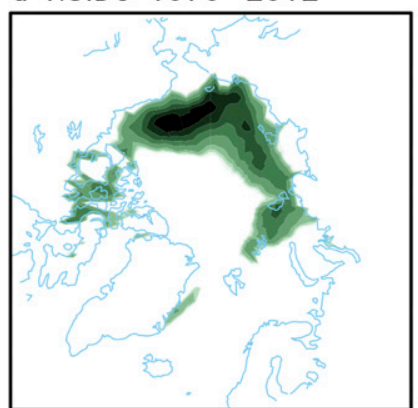

d MPI-GE 1979-2012

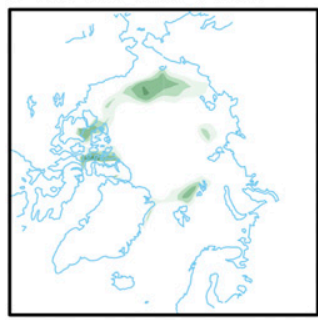

I MPI-GE 2020-2050

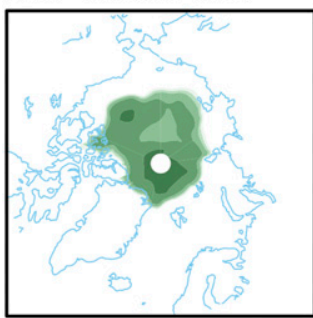

b $<4$ LE $>1979-2012$

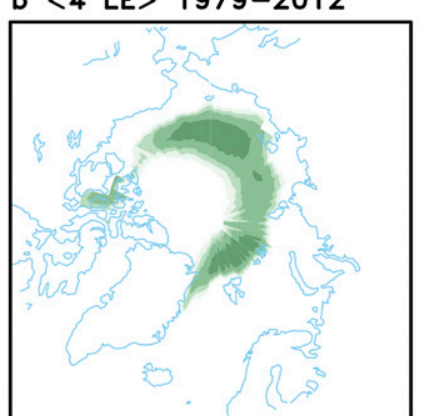

- CanESM-LE 1979-2012 f CESM-LE 1979-2012

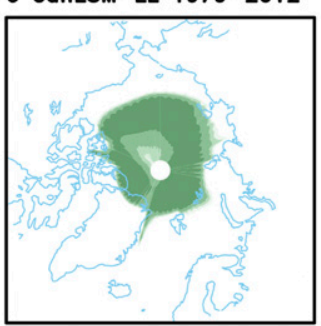

I CanESM-LE 2020-2050

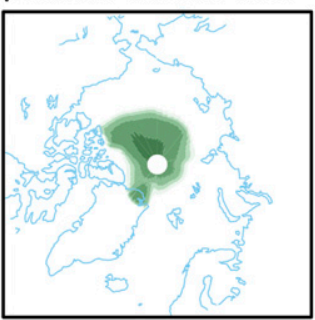

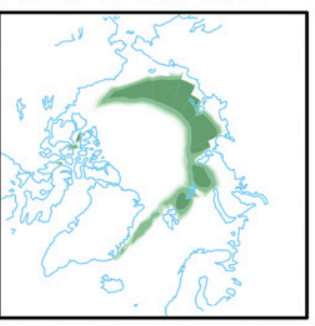

K CESM-LE 2020-2050

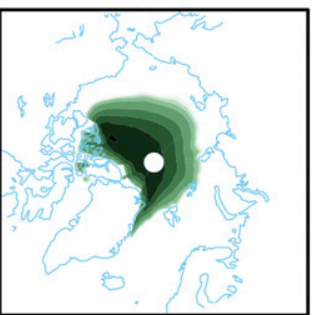

c $<31$ CMIP5 $>1979-2012$

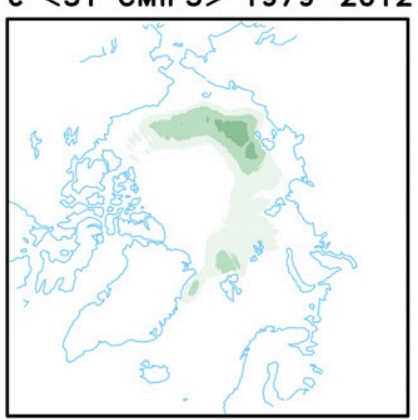

g CSIRO-LE 1979-2012

h GFDL-LE 1979-2012

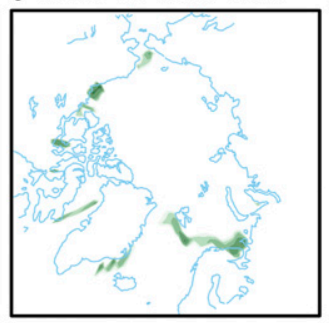

I CSIRO-LE 2020-2050

m GFDL-LE 2020-2050

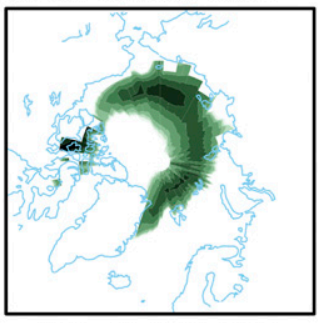

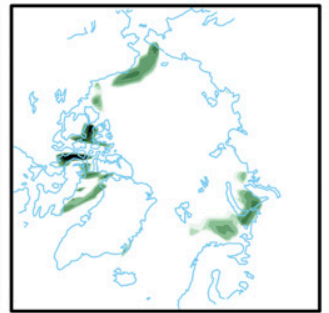
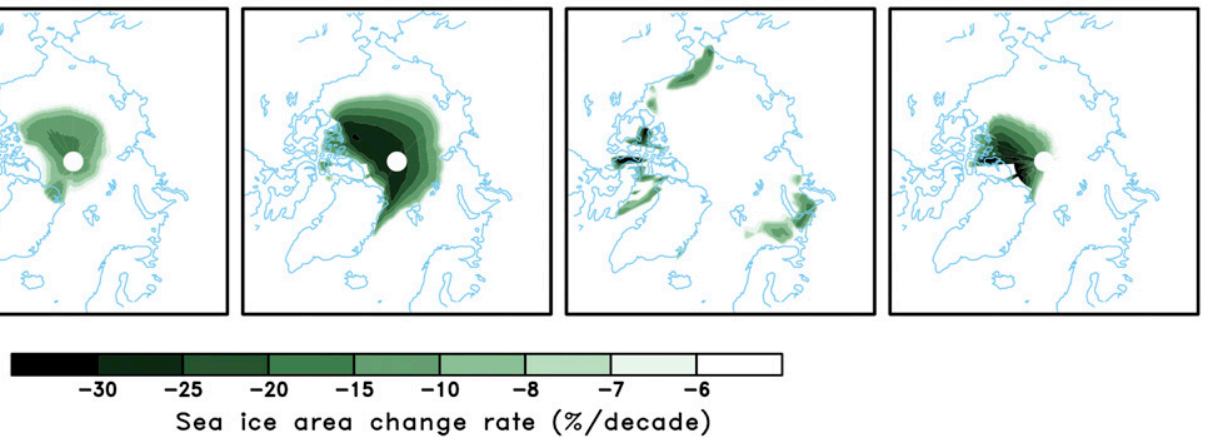

FIG. 2. Linear trend of September SIA in (a) observations (NSIDC), (b) the mean (denoted with angle brackets) of the four LEs' ensemble mean historical + RCP8.5 simulations (excluding CSIRO-LE), and (c) the mean of 31 CMIP5 historical + RCP8.5 simulations for 1979-2012. Also shown: As in (a)-(c), but for the five individual LEs' ensemble mean simulations for (d)-(h) 1979-2012 and (i)-(m) 2020-50 based on the RCP8.5 scenario.

indices between different CMIP5 models are visualized in Fig. 1g. The poor comparison between CSIRO-LE atmosphere-sea ice interactions and observations is even more clearly seen when examining the spatial pattern of the linear trend in September SIA in Fig. 2 (notice how different CSIRO-LE is from the other four LE simulations in Figs. 2g,1). Therefore, when attempting to reduce uncertainty arising from the different model physics, we will focus on the mean of only four of the five LE simulations (excluding CSIRO-LE) in the later parts of the paper. However, we note that even including CSIRO-LE in the calculation of the average does not significantly alter the results (not shown).

Figure 2 demonstrates September sea ice melting rates in observations (Fig. 2a), in the mean of the four LEs' ensemble mean (excluding CSIRO-LE, Fig. 2b), in the mean of 31 CMIP5 (Fig. 2c) and in each of the five LEs' historical (Figs. 2d-h) and future (Figs. 2i-m) ensemble mean simulations. In general, on the historical time frame the mean of four LE and the 31 CMIP5 mean model simulations share the observed sea ice melting spatial pattern, albeit with some differences in the melting trend magnitudes (Figs. $2 b, c$ ). We note that the CanESM-LE shows the strongest melt closer to the pole rather than in the marginal seas as seen in the other three LEs and in the observed record. We will show later that although each model exhibits different total SIA variability, the coupling patterns of SIA with the atmosphere from year-to-year are very similar (Figs. 3, 4), indicating that the models' bias in simulating the mean SIA is not critical to the determination of the coupling of the atmosphere to sea ice, which is mainly associated 
a ERA-I Z200 vs. SIA

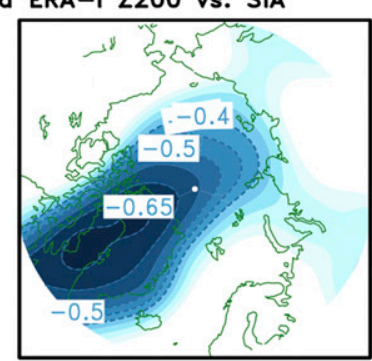

d <4 LE > Z200 vs. SIA

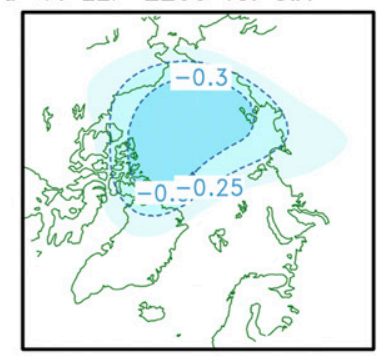

g <31 CMIP5> Z200 vs. SIA

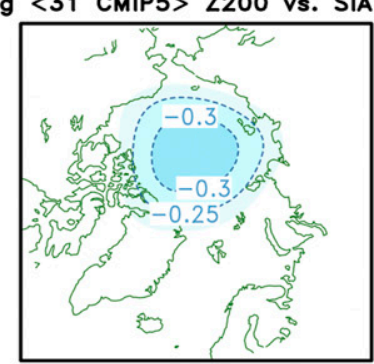

b ERA-I Height vs SIA
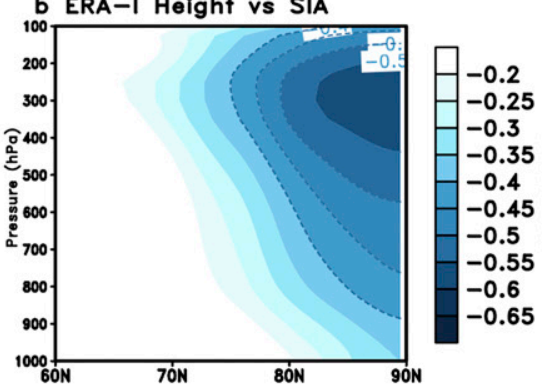

e <4 LE> Height vs. SIA
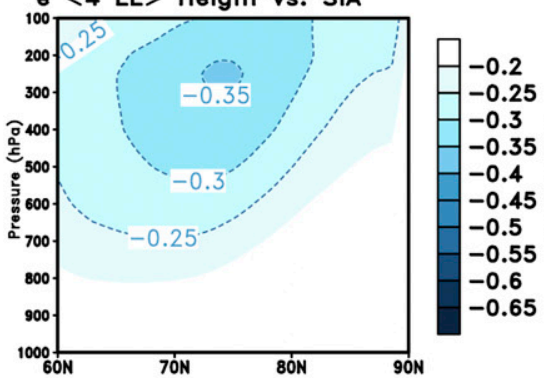

h $<31$ CMIP5 $>$ Height vs. SIA

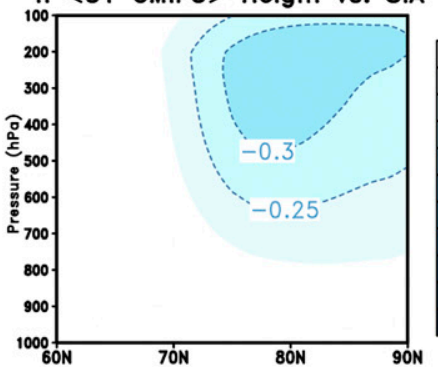

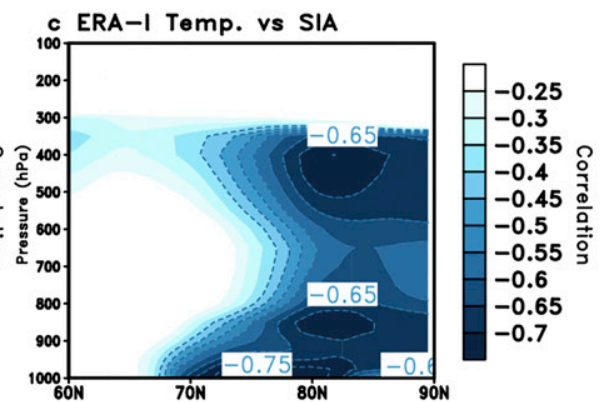

$f<4$ LE $>$ Temp. vs. SIA

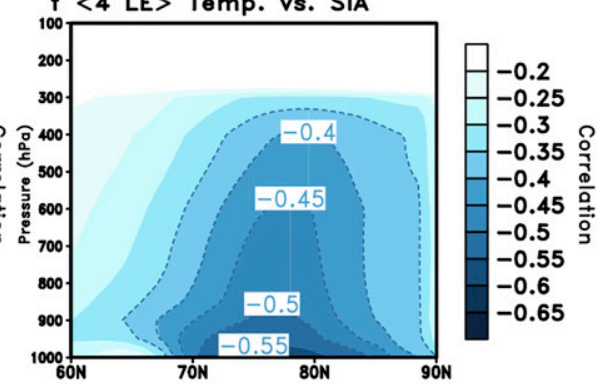

i $<31$ CMIP5> Temp. vs. SIA

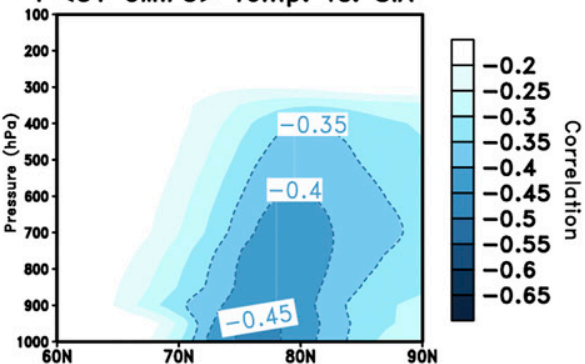

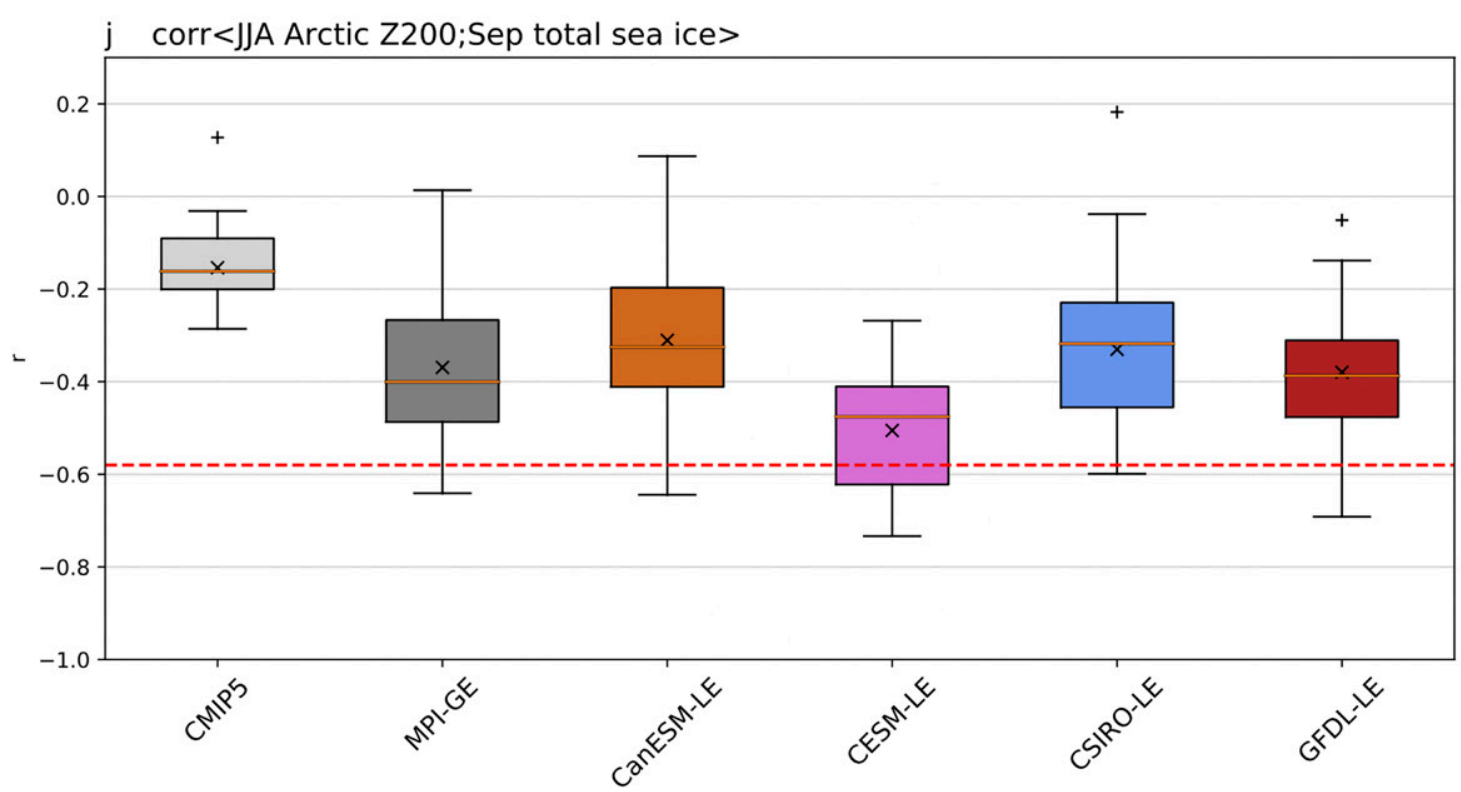

FIG. 3. Linear correlation of JJA (a) Z200, (b) zonal mean geopotential height, and (c) temperature with September total SIA index in ERA-I reanalysis for 1979-2012 (contoured values are significant at 95\% confidence level). Correlation of JJA (d) Z200, (e) zonal mean geopotential height, and (f) zonal mean temperature with September SIA index for 1979-2012 averaged over four LEs' historical + RCP8.5 runs [correlations are computed as the mean (denoted with angle brackets) of the four correlation maps (excluding CSIRO-LE) each of which is constructed as first computing correlation in each of the members of a given single-model LE and then averaging over the 
with SIA anomalies. This finding is consistent with the trend-related composites on the low-frequency time scales as well, however, seems to be contingent upon simulating the real summer mean state relatively well.

\section{Atmosphere-sea ice coupling}

\section{a. Year-to-year coupling: Observed versus simulated}

Observations reveal that in the past decades, summer sea ice variability has been driven by a remarkable rise in geopotential height above northeast Canada and Greenland with the strongest height rise occurring during 2007-12 (Ding et al. 2014, 2017, 2019; Baxter et al. 2019). The associated circulation pattern in the Arctic favors a warming and moistening (increased specific humidity) atmosphere through a circulation-driven adiabatic warming process, which likely contributed to accelerated summer sea ice melt between 2007 and 2012 (Baxter et al. 2019). To better illustrate this coupling in observations and model simulations on the year-to-year time scales, we compute the correlation of linearly detrended JJA Z200, zonal mean geopotential height, and temperature with linearly detrended September SIA index in ERA-Interim (Figs. $3 a-c)$, in the five model ensembles and in 31 CMIP5 models for 1979-2012. Correlations had first been computed in each of the ensemble members then averaged over the whole given ensemble. To get an overall picture of how models capture the observed Arctic atmosphere-sea ice coupling on interannual time scales we average the four correlation maps belonging to each of the four large ensemble simulations (Figs. 3d-f). Similarly, we average the 31 correlation maps derived from each of the individual CMIP5 model historical + RCP8.5 runs (Figs. 3g-i). We also show correlations between Arctic area-averaged (north of $60^{\circ} \mathrm{N}$ ) JJA Z200 and total September SIA index for the CMIP5 multimodel and five single-model ensembles' individual members (Fig. 3j). In Fig. 4 correlations calculated for each of the five individual LE mean simulations are additionally presented.

Figures 3 and 4 show that September SIA index is negatively correlated with both JJA upper-level geopotential height and lower-midtropospheric temperature in both observations and the CMIP5 multimodel or single-model ensemble mean simulations. This corresponds to the inverse relationship between temperature or geopotential height and sea ice changes. However, the magnitude of the correlation is consistently underestimated by all models, especially in the cases of the CSIRO-LE and the CanESM-LE, which, in line with the lack of a correctly resembled summer mean sea ice state (Fig. 2g) or melting spatial pattern (Figs. 2e,g), appear to show less strong interannual atmosphere-sea ice connection (Figs. 4d,e,j,k). Figure 3j demonstrates that the ensemble spread is the largest for the CanESM-LE and the CSIRO-LE, relative to the size of the ensembles, and these models show the least negative correlations across their members. Additionally, all large ensembles show improvements relative to the CMIP5 ensemble and the CESM-LE appears the best in resembling the observed correlation. Observations reveal stronger interannual coupling between sea ice and both upper-level geopotential heights $(-0.65$ vs -0.3$)$ and lower-tropospheric temperatures $(-0.75 \mathrm{vs}-0.5)$ than the models (Fig. 3). We find that the difference between the models and observations is greater if we compare summertime temperature values and September sea ice than doing so with the annual means as presented by Olonscheck et al. (2019).

Overall, both the perturbed initial condition and CMIP5 models capture the observed interannual coupling of Arctic summertime circulation and September sea ice variability but with weaker magnitudes and with a somewhat different horizontal Z200 and vertical height/temperature profiles, which is an important limitation common to all the models (Figs. 3, 4). Thus, our analysis suggests that simulated sea ice appears to be less sensitive to changes in the atmosphere than observed in the past 40 years (Ding et al. 2017).

\section{b. Low-frequency atmosphere-sea ice coupling from 1979 to 2012}

Figures 3 and 4 demonstrate that the notable atmospheresea ice coupling seen in year-to-year observations is generally captured in model simulations, albeit with some prominent structural differences. The same circulation-driven process

\footnotetext{
$\longleftarrow$

whole given LE]. Correlation of JJA (g) Z200, (h) zonal mean geopotential height, and (i) zonal mean temperature with September SIA index for 1979-2012 averaged (denoted with angle brackets) over 31 CMIP5 models' historical + RCP8.5 runs (correlations are first computed in each of 31 models, and then the 31 correlation patterns are averaged to construct a 31-member multimodel ensemble). Contours in (d)-(i) do not represent significance because we do not account for the significance of the averaged correlation maps. (j) Correlation of Arctic area-averaged $\left(60^{\circ}-90^{\circ} \mathrm{N} ; 0^{\circ}-359^{\circ} \mathrm{E}\right) \mathrm{JJA} \mathrm{Z} 200$ and September SIA index in each of the members of the five LE simulations: the whiskers extend to $1.5 \times$ IQR. Crosses mark average values; plus signs mark the outliers (outside $1.5 \times$ IQR). The median is indicated with an orange horizontal line. The red dashed line indicates the ERA-I correlation value $(r=-0.58)$. All variables are linearly detrended before calculating correlations.
} 
a MPI-GE Z200 vs. SIA

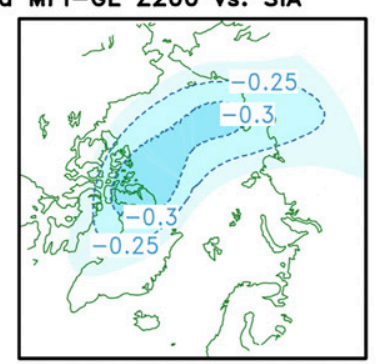

d CanESM-LE Z200 vs. SIA

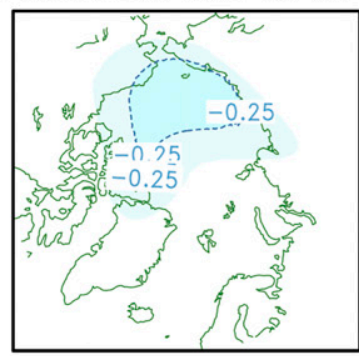

g CESM-LE Z200 vs. SIA

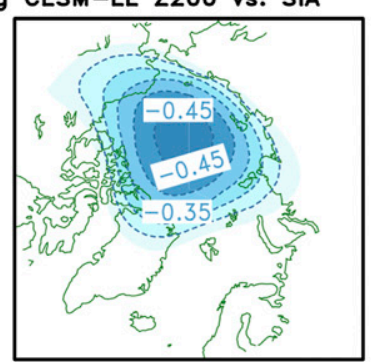

I CSIRO-LE Z200 vs. SIA

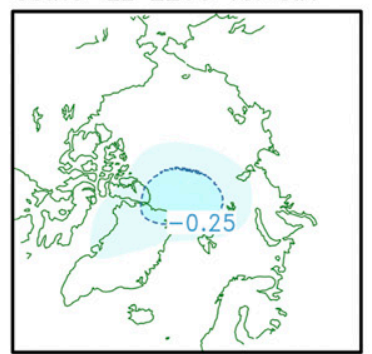

m GFDL-LE Z200 vs. SIA

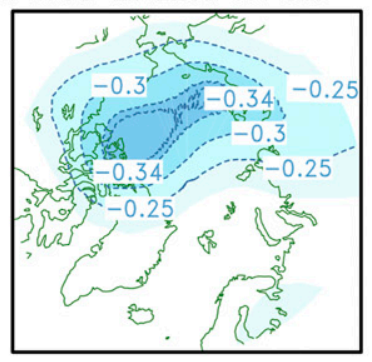

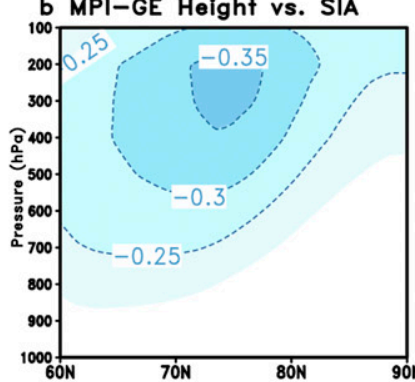

e CanESM-LE Height vs. SIA

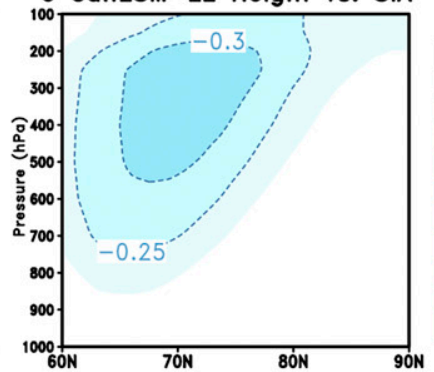

h CESM-LE Height vs SIA

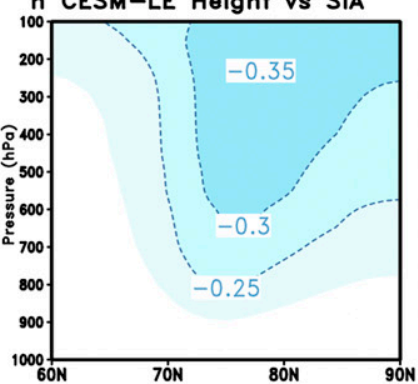

k CSIRO-LE Height vs. SIA

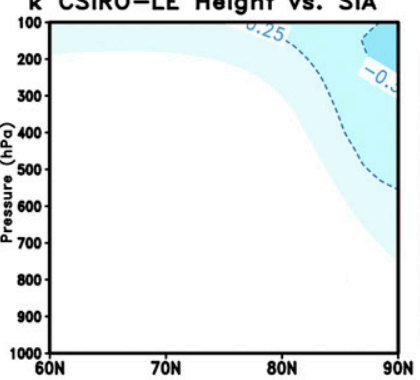

n GFDL-LE Height vs. SIA

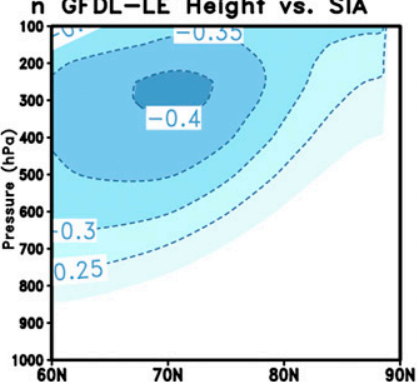

c MPI-GE Temp. vs SIA
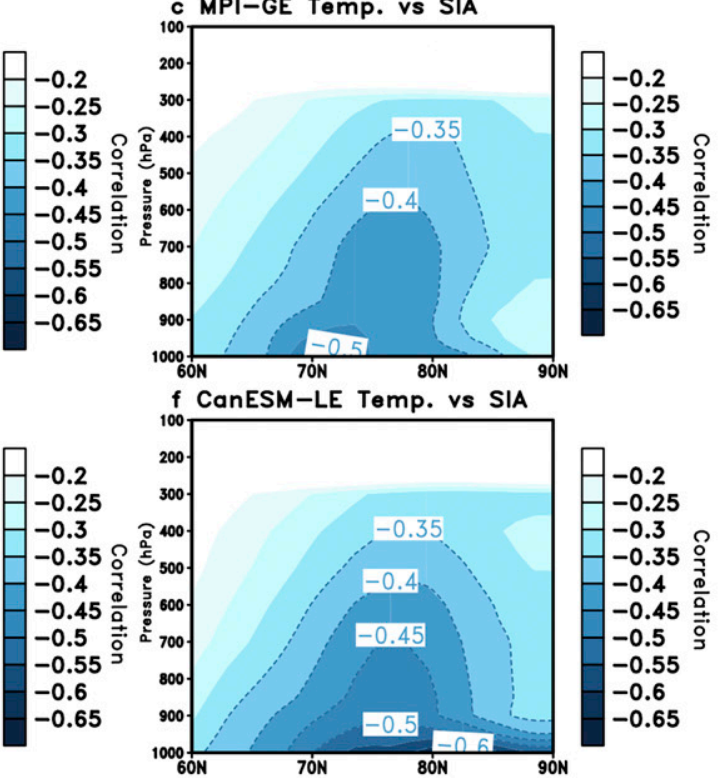

i CESM-LE Temp. vs SIA
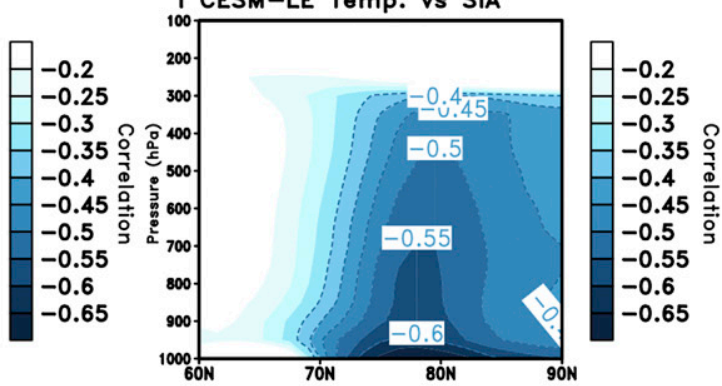

I CSIRO-LE Temp. vs SIA
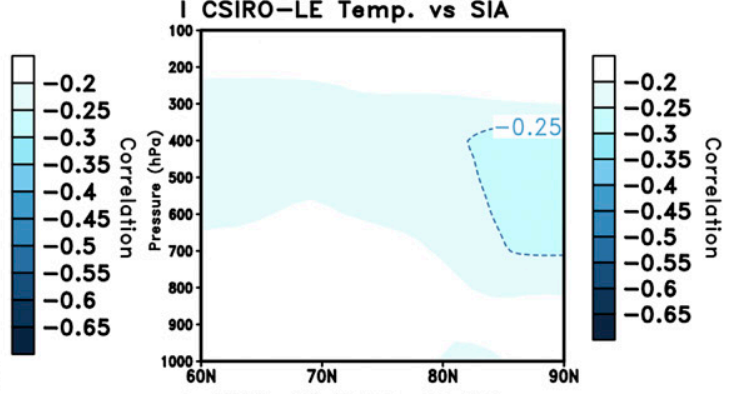

- GFDL-LE Temp. vs SIA

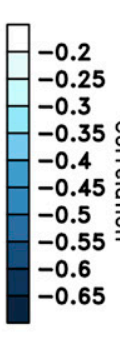

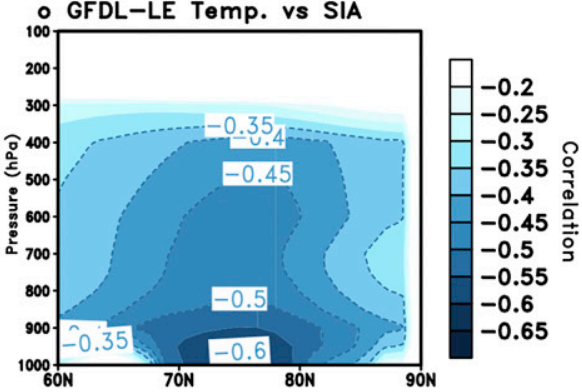

FIG. 4. Linear correlation of JJA (left) Z200, (center) zonal mean geopotential height, and (right) zonal mean temperature with September SIA index using the five LEs: (a)-(c) MPI-GE, (d)-(f) CanESM-LE, (g)-(i) CESM-LE, (j)-(l) CSIRO-LE, and (m)-(o) GFDL-LE. Correlations are first computed in each of the members of a given single-model LE and then are averaged over the whole given LE. Contours do not represent significance because we do not account for the significance of the averaged correlation maps. All variables are linearly detrended before calculating correlations. 


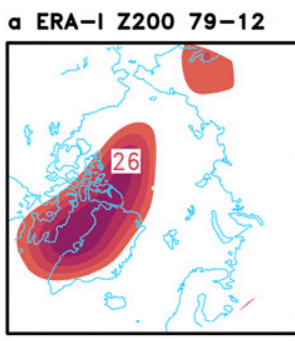

e $<$ Z200 diff.> 79-12

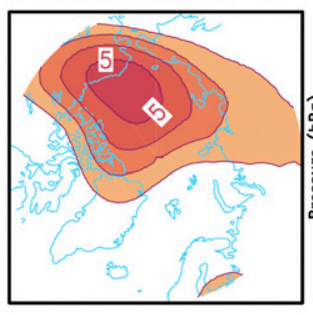

I <Z200 Forced $>$ 79-12

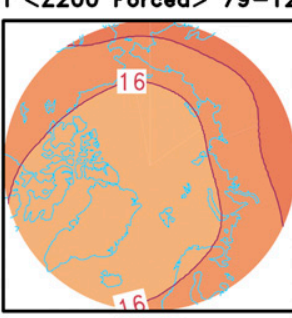

b ERA-I Height 79-12

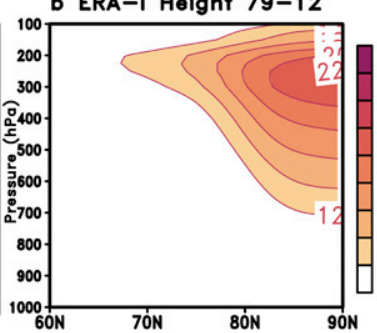

f <Height diff.> 79-12

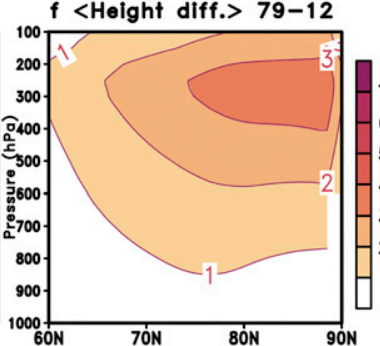

I < Height Forced> 79-12

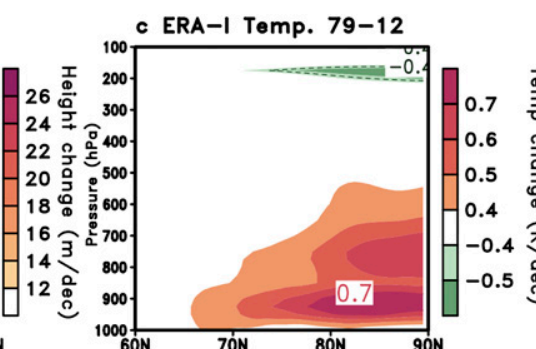

<Temp. diff.> 79-12

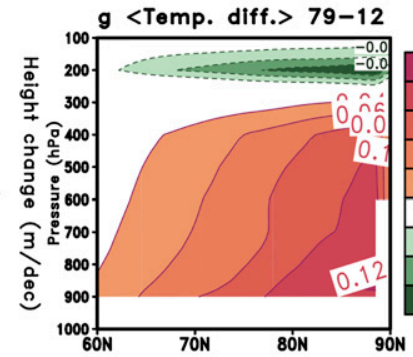

k <Temp. Forced> 79-12
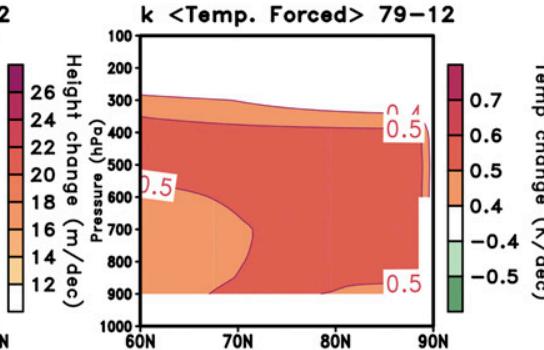

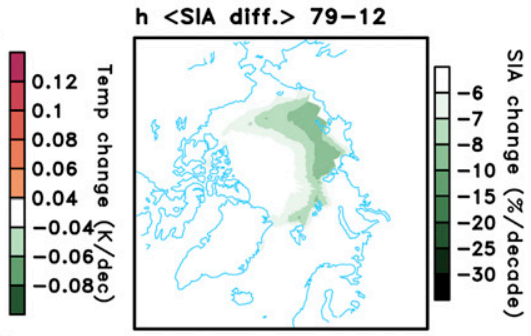

I <SIA Forced $>79-12$

d NSIDC SIA trend 79-12

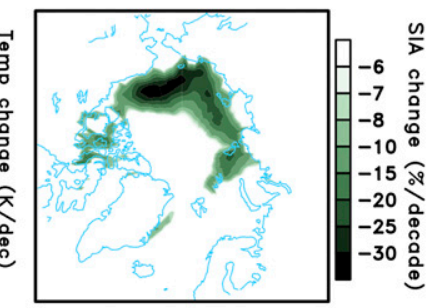

$h<$ SIA diff. $>79-12$

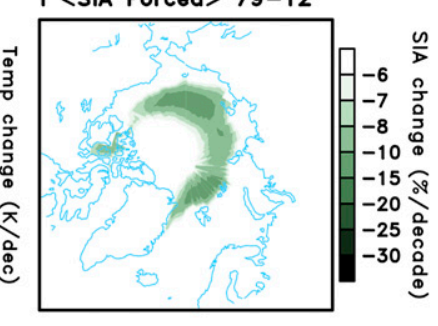

FIG. 5. Observed (ERA-Interim/NSIDC) (a) Z200, (b) zonal mean geopotential height, (c) zonal mean temperature, and (d) September SIA linear trends for 1979-2012. Historical (e) Z200, (f) zonal mean geopotential height, (g) zonal mean temperature and (h) September SIA fast-minus-slow composite trends and the ensemble mean (i) Z200, (j) zonal mean geopotential height, (k) zonal mean temperature and (1) September SIA trends averaged over the four LE historical + RCP8.5 experiments for 1979-2012 [excluding CSIRO-LE; the mean of four Z200, height, temperature, and sea ice either fast-minus-slow composite or ensemble mean (forced) trends is denoted with angle brackets]. Note the color bar differences between the composite in (e)-(g) and the forced [in (i)-(k)] or observed [in (a)-(c)] trend magnitudes.

may also be important on low-frequency time scales as Ding et al. (2019) already showed for both observations and the CESM-LE. Because the Z200, zonal mean geopotential height $Z$, and zonal mean temperature $T$ fast-minus-slow composites reflect the coupling between trends in the atmospheric variable and sea ice, we can compare the composite trend patterns to the ones obtained previously with correlation analysis and use the similar features of the two to assume an alike physical mechanism over the two time scales. Thus, to reach a more comprehensive understanding of how JJA atmospheric circulation can drive September sea ice variability independent from the different modeling environments, we further examine the long-term behavior of this atmospheric process utilizing the fast-minus-slow composites of JJA Z200, Z, T, and September SIA derived from historical, future, or preindustrial runs of the available climate simulations and compare them to observations.

We first show the observed linear trends of JJA Z200, $Z, T$, and September SIA in the Arctic for 1979-2012
(Figs. 5a-d). Based on Figs. 5a-c for the past four decades, the Arctic summer circulation has been dominated by an atmospheric process resembling an anticyclone centered above Greenland and northeast Canada, which can cause tropospheric warming on top of the local anthropogenically forced temperature rise. This observed circulation pattern is reproduced in the mean of four LE simulations' historical fast-minus-slow composites (Figs. 5e-g) rather well, in contrast with the linear trend patterns derived from the ensemble mean (forced component) simulations, which show uniform height rise and warming in the Arctic without any regional anticyclonedriven features (Figs. 5i-k). We note that the composite trend magnitudes (Figs. 5e-g) are markedly weaker than the observed trend magnitudes (Figs. 5a-c) suggesting that internal atmospheric variability may play a key role in the observed summer circulation changes; however, models exhibit limitations in fully capturing the magnitude of the internal atmospheric process. Because the 
spatial patterns of changes in the atmospheric variables on the low-frequency time scales (Figs. 5e-g) strongly resemble the ones we have seen in the atmosphere-sea ice correlation maps (Figs. 3, 4), the weaker composite magnitudes may be related to the tendency for models to underestimate atmosphere-sea ice correlations (Figs. 3, 4) relative to observations. This can be a consequence of a shared physical mechanism over the two time scales (Ding et al. 2017).

For further investigation we also compute the mean of four LEs' fast-minus-slow composite of September SIA to extract the internal trend component of sea ice melt (Fig. 5h) and compare it to the forced component (Fig. 51). Although the mean of the four LE simulations' $Z$ or $T$ composite trend magnitudes are smaller by a factor of 3-4 relative to the corresponding forced component magnitudes (Figs. 5e-g vs Figs. 5i-k), the difference between the internal and the forced sea ice melting pattern magnitudes or spatial distributions is less pronounced. The fact that the prominent difference between internal and forced atmospheric trend magnitudes does not result in large differences between forced and internal sea ice melting rates further emphasizes the necessity to search for associated atmospheric changes to understand the underlying mechanism responsible for the melting.

Evidence for sea ice-related atmospheric changes can also be found in the individual LE simulations' and 31 CMIP5 preindustrial control simulations' composite patterns for 1979-2012 in Figs. 6 and 7. During 19792012, three of the five LE experiments' fast-minus-slow SIA composites (except for the CanESM-LE and the CSIRO-LE) resemble the observed sea ice melting spatial pattern with the strongest melting occurring round the edge of the Arctic basin with a corresponding high pressure in the upper troposphere and surface warming (Fig. 6). Notably, the CanESM-LE-which shows the strongest sea ice melt in the central Arctic-and the CSIRO-LE—with only weak year-to-year coupling — both share the features of the observed atmospheric process in the fast-minus-slow composites albeit with some differences, especially in the sea ice composites because of the model's lack of a realistic summer mean state (CSIROLE) or the biased spatial melting pattern (CanESM-LE, CSIRO-LE). Importantly, the same patterns representing the low-frequency atmosphere-sea ice coupling are reproduced in the pseudoensemble of 31 CMIP5 preindustrial runs without the presence of anthropogenic forcing (Fig. 7).

With the qualitative analysis of historical and preindustrial fast-minus-slow composites in the various model experiments we have shown robust evidence that the regional barotropic height increase over the Arctic in summer due to internal variability-via an adiabatic warming process-also dominates summer sea ice variability on low-frequency time scales in both the real- and pseudoensemble simulations (Figs. 5-7; Wernli and Papritz 2018; Ding et al. 2019). Our results further support the findings of Ding et al. (2019) that this internal atmospheric process is a contributor to sea ice melt across different model environments. We have also drawn attention to the fact that current climate models possibly underestimate the strength of atmosphere-sea ice coupling relative to the observed one in ERA-I on both year-to-year and low-frequency time scales. The weaker year-to-year coupling of sea ice with the atmosphere (Figs. 3, 4) may indicate a weaker coupling mechanism in the trend-related composites as well. In ERA-I, the maximum JJA Z200 change over 1979-2012 in the Arctic is $26 \mathrm{~m}$ decade $^{-1}$ whereas models show only $4-7 \mathrm{~m} \mathrm{decade}^{-1}$ in the fast-minus-slow composites and the maximum JJA TS change over 1979-2012 in the Arctic is $0.6^{\circ} \mathrm{C}$ decade $^{-1}$ whereas models show only $0.12^{\circ} \mathrm{C}$ decade $^{-1}$ in the fast-minus-slow composites. The relative role of the internal component, therefore, needs further estimation; however, our results indicate that models fail to replicate the full strength of the observed atmosphere-sea ice connection.

\section{c. Low-frequency atmosphere-sea ice coupling from 2020 to 2050}

How this atmospheric process, identified in observations and historical/preindustrial model simulations, will behave in the future, has so far been unaddressed in the literature. Therefore, we now evaluate the fast-minusslow composites in all the available future scenario runs of the five large ensembles for 2020-50.

In general, the mean of the fast-minus-slow composites corresponding to the four models' (excluding the CSIRO-LE) RCP8.5 scenarios (Figs. 8a-c), unlike the forced model component linear trends (Figs. 8e-g), are reminiscent of the atmospheric structure that dominates sea ice variability on interannual to interdecadal time scales in observations, historical and preindustrial model simulations. Similar to the historical period, all individual models show high pressure in the Arctic upper troposphere along with surface warming concomitant to sea ice loss (Fig. 9). The composite trend magnitudes are comparable to the small historical and preindustrial composite magnitudes (relative to the observed trends). We suggest that the small magnitudes seen in the future fast-minus-slow composites (Figs. 8a-c, 9) may also be connected to the underestimated atmosphere-sea ice interannual coupling (Figs. 3, 4) rooted in the model's physics.

Examining the mean of four LEs' September SIA composites we can also see that future sea ice melt occurs over the Arctic Ocean, north of Greenland, and 
a MPI-GE Z200 diff.
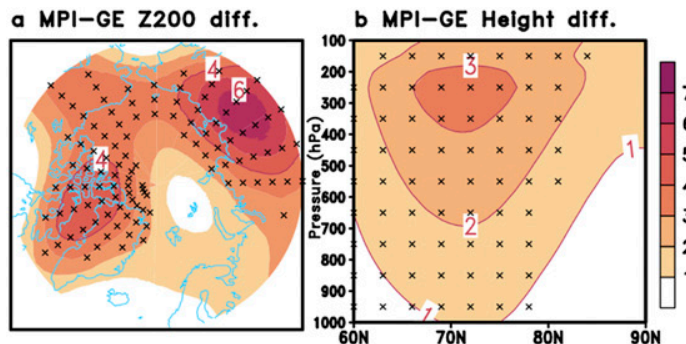

- CanESM-LE Z200 diff.
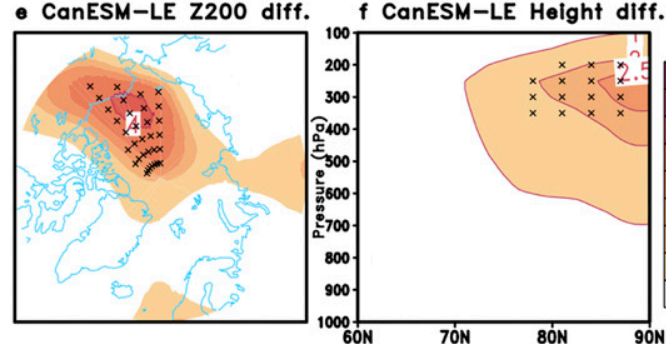

I CESM-LE Z200 diff.

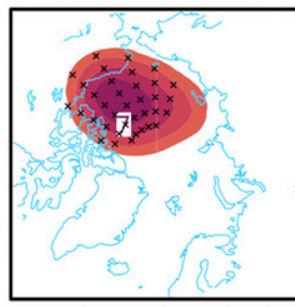

I

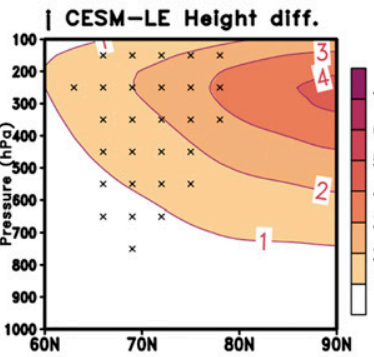

$m$ CSIRO-LE Z200 diff.
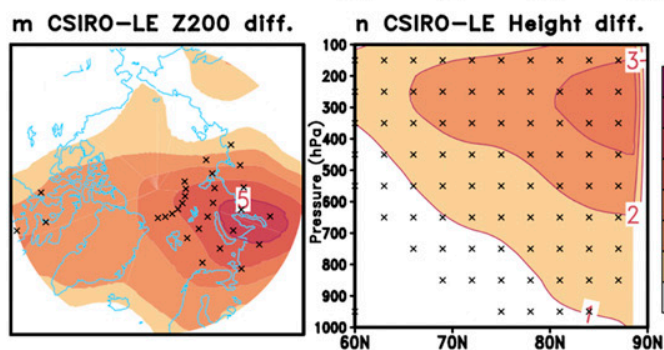

r GFDL-LE Height diff.
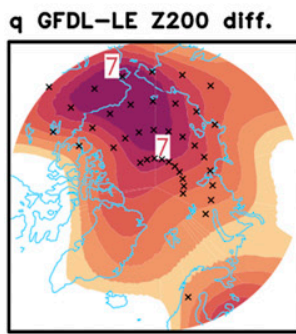
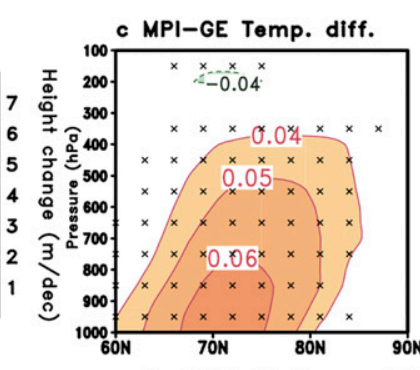

g CanESM-LE Temp. diff.

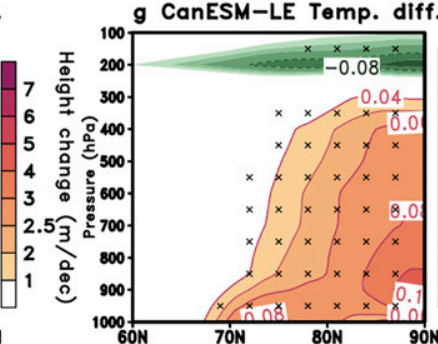

k CESM-LE Temp. diff.
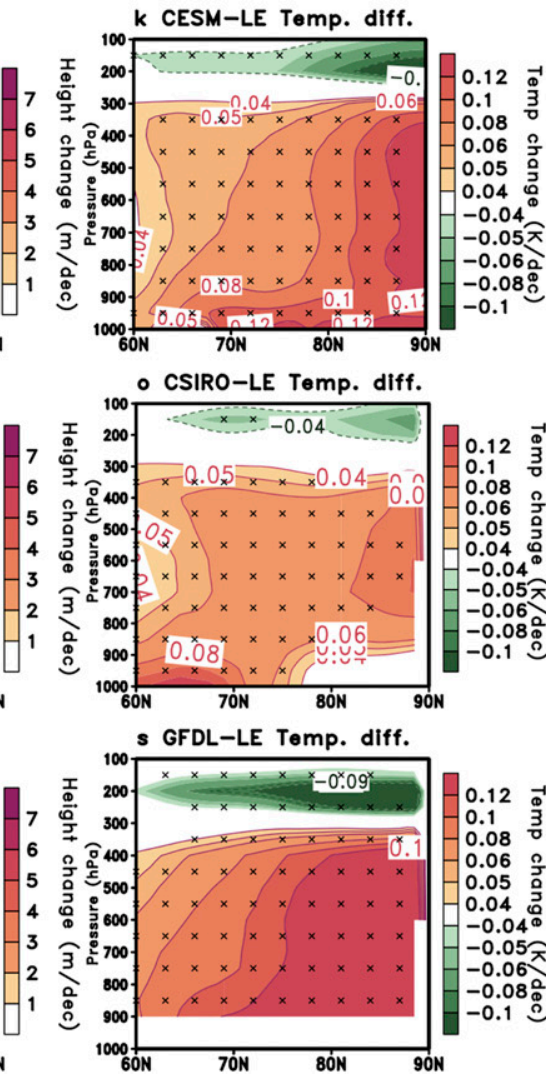

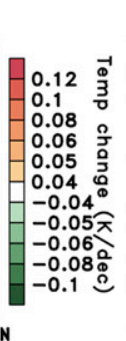

d MPI-GE SIA diff.

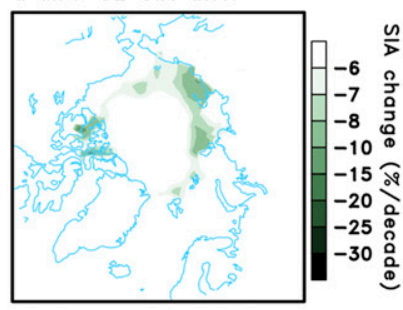

h CanESM-LE SIA diff.

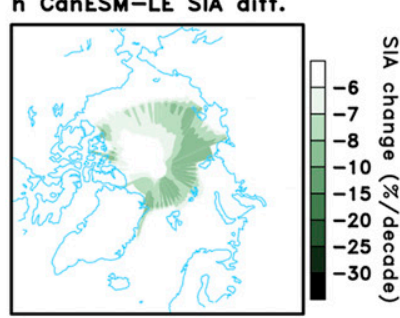

I CESM-LE SIA diff.

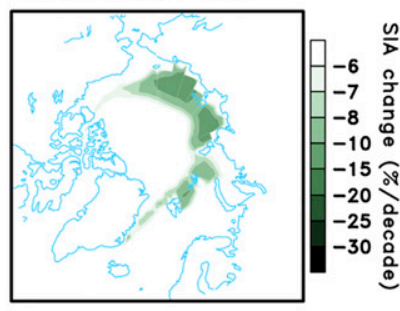

P CSIRO-LE SIA diff.

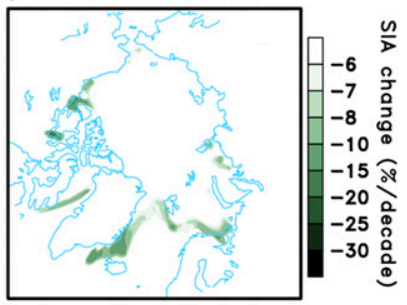

† GFDL-LE SIA diff.

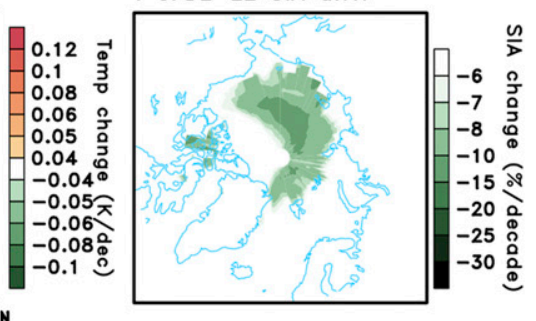

FIG. 6. Historical fast-minus-slow composite trend plots of JJA (left) Z200, (left center) zonal mean geopotential height, (right center) zonal mean temperature, and (right) September SIA for the five LEs' historical + RCP8.5 experiments for 1979-2012: (a)-(d) MPI-GE, (e)-(h) CanESM-LE, (i)-(l) CESM-LE, (m)-(p) CSIRO-LE, and (q)-(t) GFDL-LE. Crosses indicate significance on the 95\% confidence level (two-sample $t$ test).

Canada in the internal component reminiscent of the ensemble mean SIA trends (forced component) (Figs. 8d,h). Despite minor differences in the magnitudes and spatial patterns of sea ice melt between the forced and internal sea ice trend components (Fig. 8d vs Fig. 8h) the atmospheric circulation patterns differ considerably (Figs. $8 \mathrm{a}-\mathrm{c}$ vs Figs. 8e-g). Also, models show discernible sea ice melt during 2020-50 relative to 1979-2012 (Fig. 2), whereas 

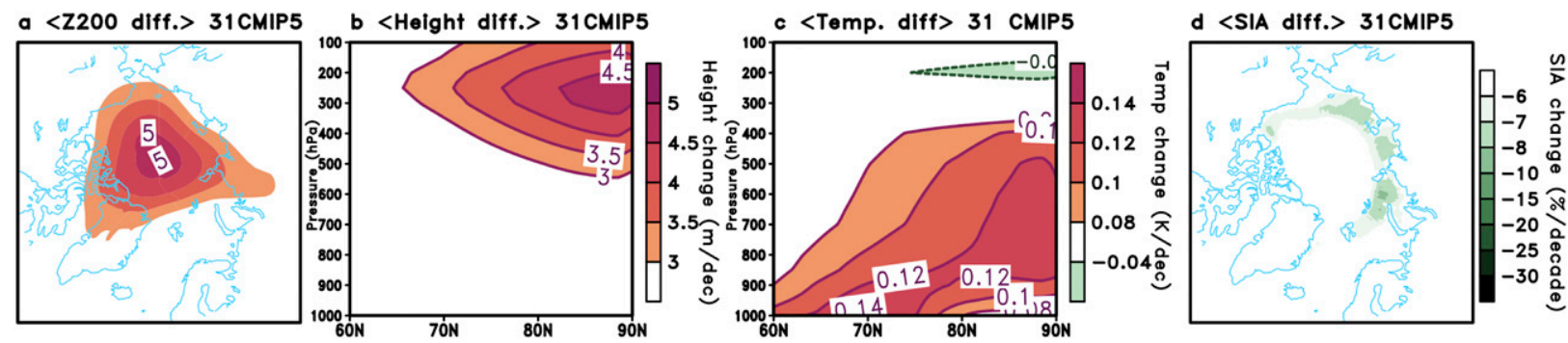

FIG. 7. The mean (denoted with angle brackets) of 31 fast-minus-slow (a) Z200, (b) zonal mean geopotential height, (c) zonal mean temperature and (d) September SIA composites constructed using each 34-yr-long period of long preindustrial control integration of 31 individual CMIP5 models, also known as the pseudoensemble method (see section 2f).

the differences in the magnitude of sea ice associated atmospheric changes are not so pronounced between the two periods (Figs. 6, 9). These suggest that circulation may be of key importance in driving future sea ice loss and raise the question of whether improvements in modeled atmosphere-sea ice connections will help us to quantify the relative role for internal variability in the ongoing Arctic climate change along with improve the accuracy of modeled sea ice sensitivity (Zelinka et al. 2020; SIMIP Community 2020; Winton 2011).

\section{d. A role for the differing amount of external forcing}

When addressing future changes in the climate system the impact of anthropogenic forcing is a key issue. To address the question of how the identified internal atmospheric process may be influenced by external forcing with different intensity, we perform supplementary calculations and show evidence that-according to the fast-minus-slow composites derived from each of the three RCP scenarios of MPI-GE for 2020-50- the circulation-driven process exists in all three forcing experiments (Fig. 10). Furthermore, in the case of the RCP4.5 scenario the composite trend magnitudes (for Z200, $Z$ and $T$ ) are larger (Figs. 10d-f) relative to the RCP2.6 (Figs. 10a-c). However, interestingly, the RCP8.5 scenario again shows smaller trend magnitudes (Figs. 10g-i) comparable to the RCP2.6. This might be indicative of a nontrivial response of the atmospheric process's strength to the external forcing with different intensities and that there might exist an optimal amount of external forcing in the model when sea ice is more sensitive to changes in the atmosphere than other forcing scenarios. However, the
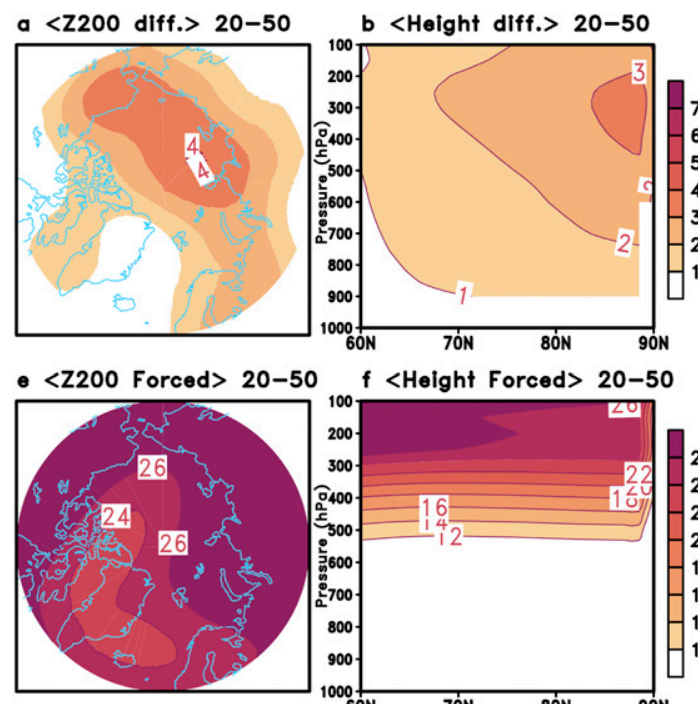

$f<$ Height Forced> 20-50
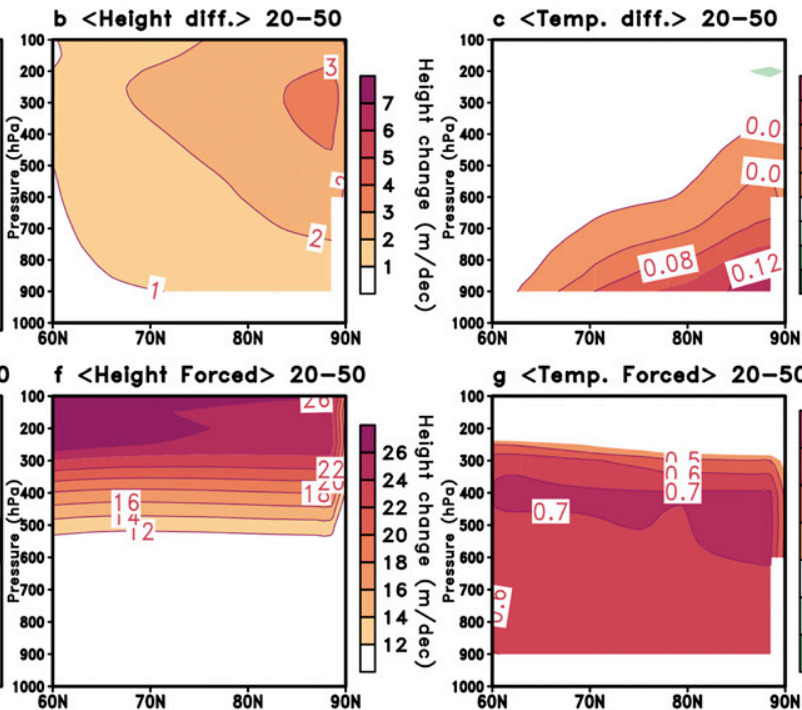

g <Temp. Forced> 20-50
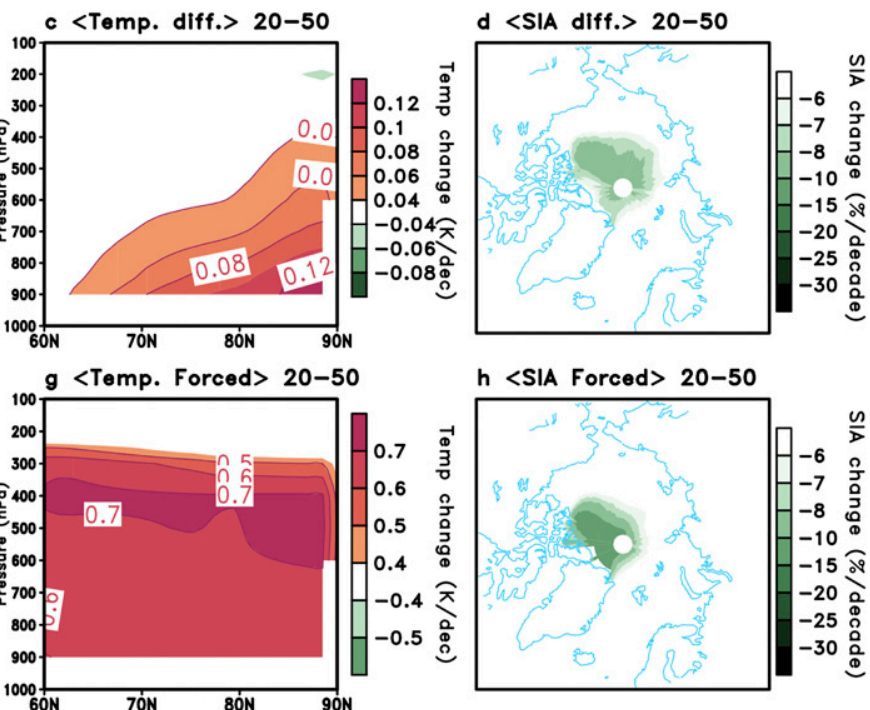

h $<$ SIA Forced $>$ 20-50

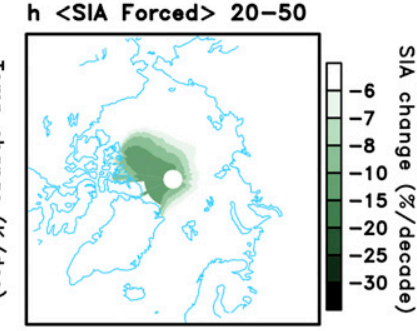

FIG. 8. Future (a) Z200, (b) zonal mean geopotential height, (c) zonal mean temperature and (d) September SIA fast-minus-slow composite trends and the ensemble mean (e) Z200, (f) zonal mean geopotential height, (g) zonal mean temperature and (h) September SIA trends averaged over four large ensembles' RCP8.5 experiments for 2020-50 [excluding CSIRO-LE; the mean of each of the four Z200, height, temperature, and sea ice either fast-minus-slow composite or ensemble mean (forced) trends is denoted with angle brackets]. Note the color bar differences between (e)-(g) and (a)-(c). 
a MPI-GE Z200 diff.
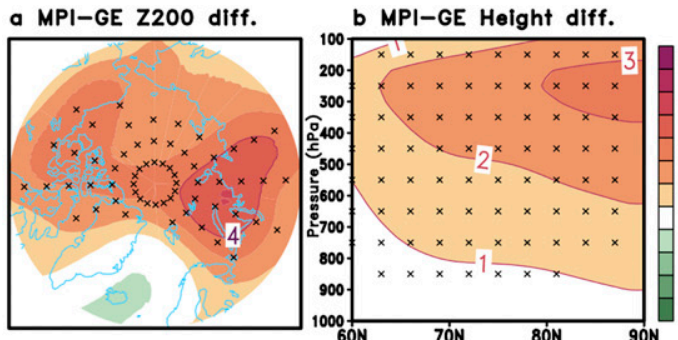

- CanESM-LE Z200 diff.

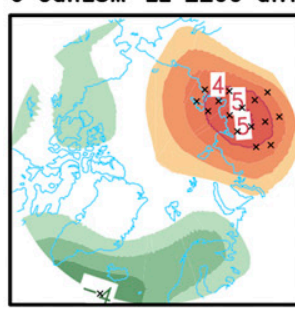

I CESM-LE Z200 diff.

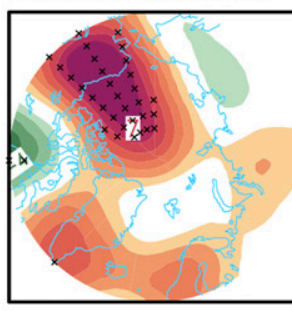

m CSIRO-LE Z200 diff.

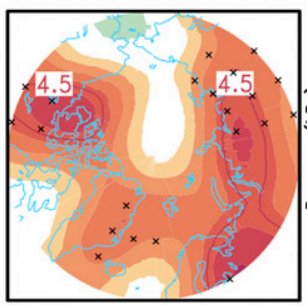

q GFDL-LE Z200 diff.

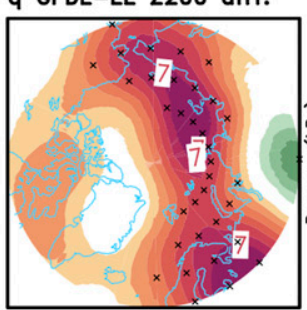

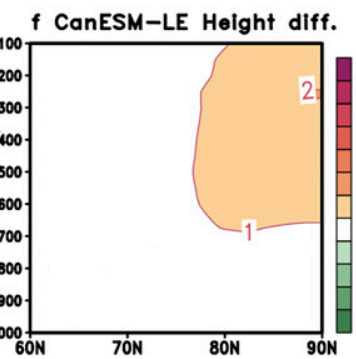

I CESM-LE Height diff.

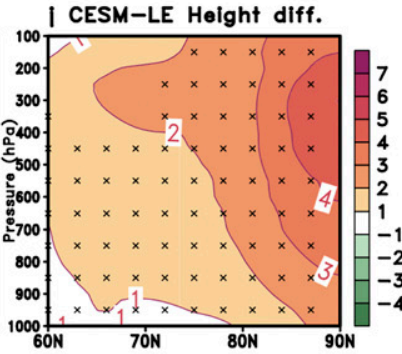

n CSIRO-LE Height diff.

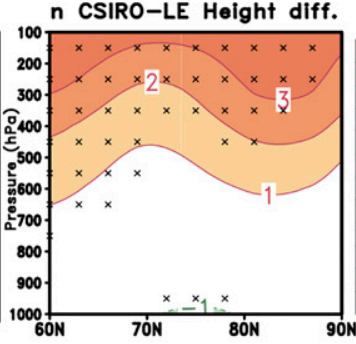

$r$ GFDL-LE Height diff.

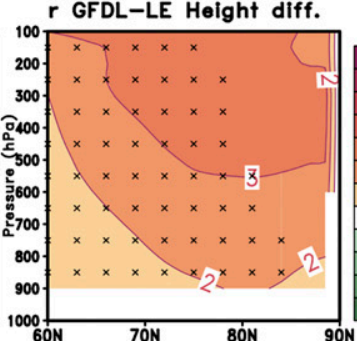

c MPI-GE Temp. diff.

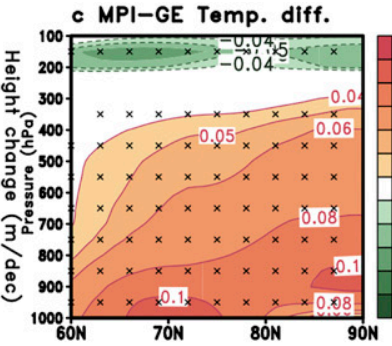

g CanESM-LE Temp. diff.

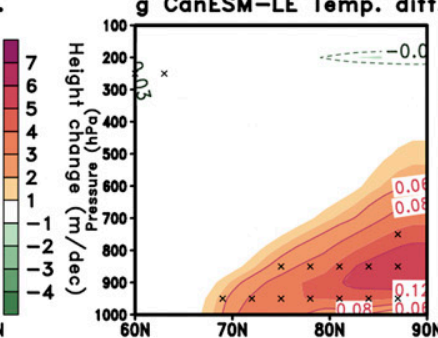

k CESM-LE Temp. diff.

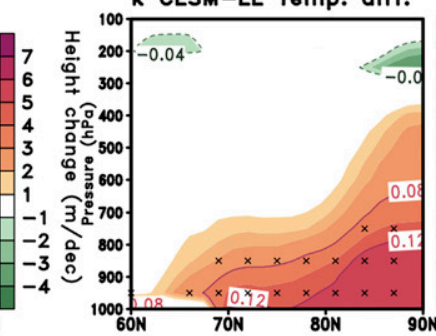

- CSIRO-LE Temp. diff.

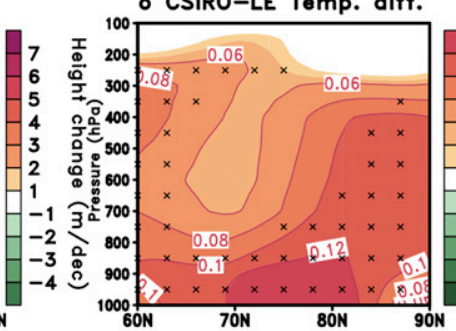

s GFDL-LE Temp. diff.

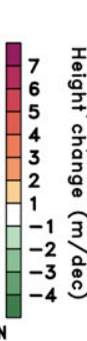

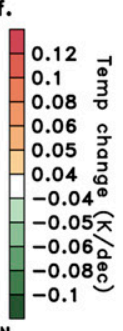
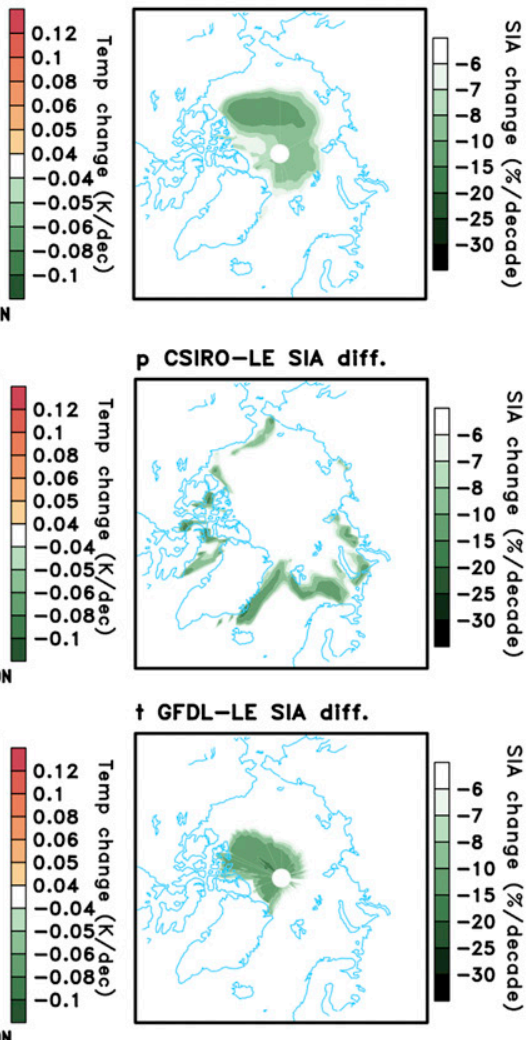

h CanESM-LE SIA diff.

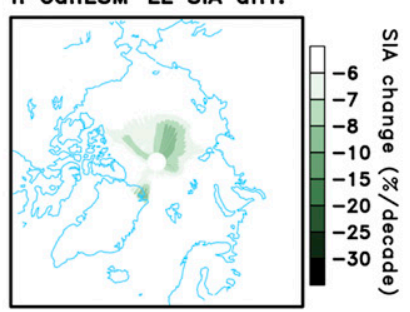

I CESM-LE SIA diff.

P CSIRO-LE SIA diff.

d MPI-GE SIA diff.
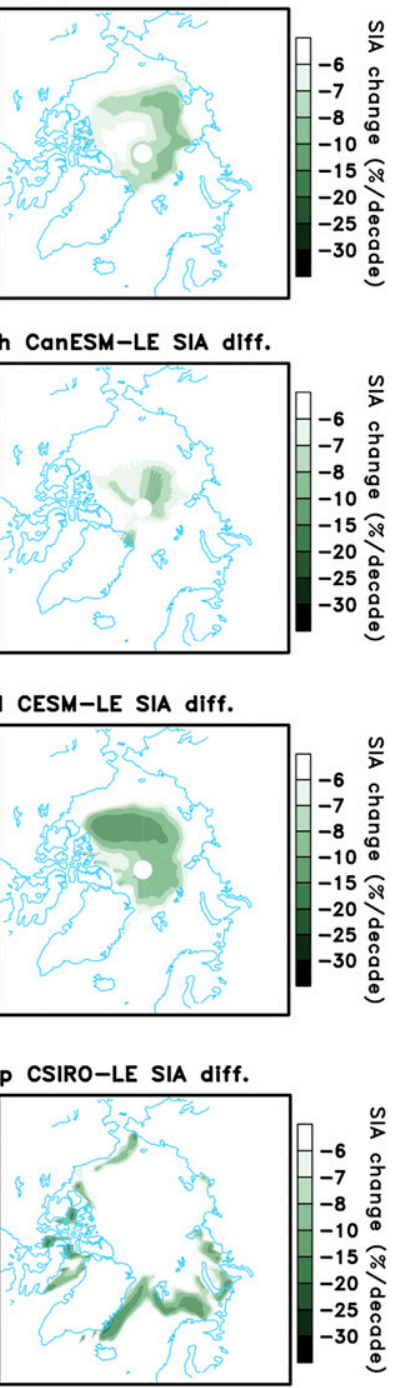

† GFDL-LE SIA diff.

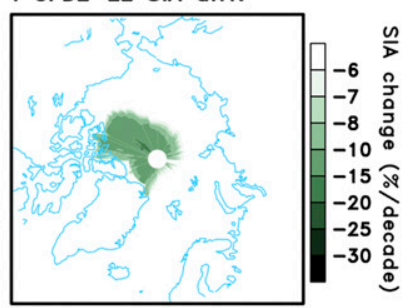

FIG. 9. Future fast-minus-slow composite trend plots of JJA (left) Z200, (left center) zonal mean geopotential height, (right center) zonal mean temperature, and (right) September SIA for the five LEs' RCP8.5 experiments for 2020-50: (a)-(d) MPI-GE, (e)-(h) CanESM-LE, (i)-(l) CESM-LE, (m)-(p) CSIRO-LE, and (q)-(t) GFDL-LE. Crosses indicate significance on the $95 \%$ confidence level (two-sample $t$ test).

extent to which the response of the coupling to the different intensity of external forcing is nontrivial needs further study particularly using other models with differing external forcing scenarios. Taken together, these lines of evidence suggest a strong role for the internal atmospheric process in driving sea ice loss with some yet-to-bedetermined contribution from the differing intensity of external forcing in the upcoming decades. 
a RCP2.6 Z200 diff.

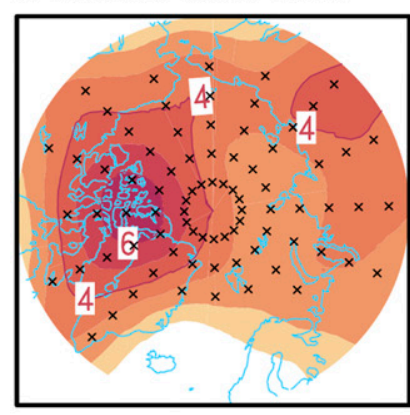

d RCP4.5 Z200 diff.

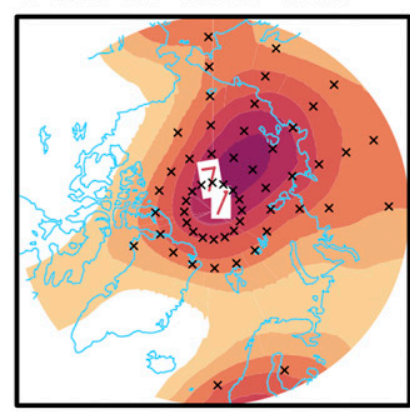

g RCP8.5 Z200 diff.

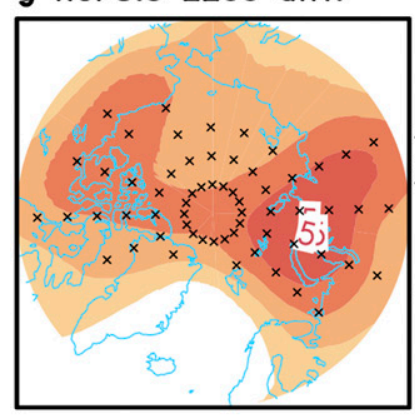

| $<$ Z200 diff. $>$

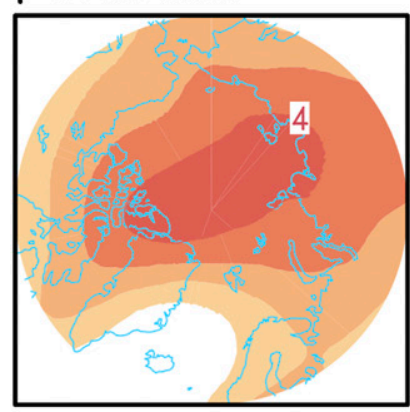

b RCP2.6 Height diff.

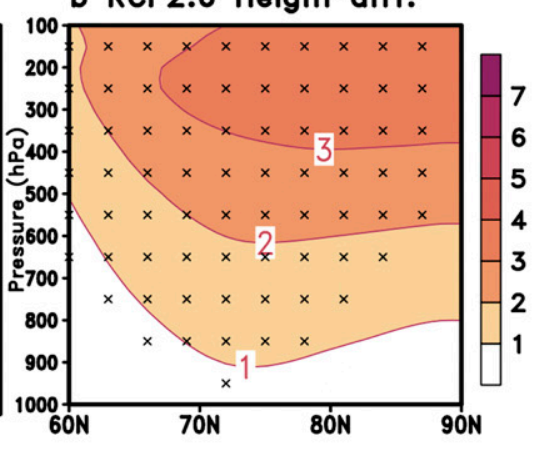

RCP4.5 Height diff.

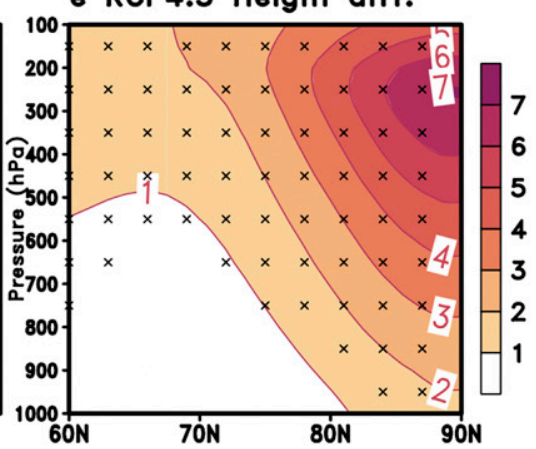

h RCP8.5 Height diff.

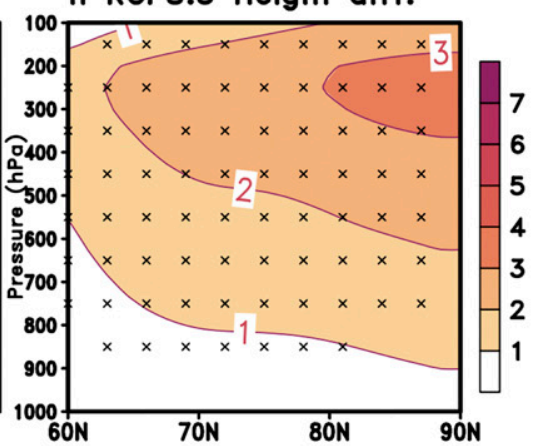

$k$ <Height diff.>

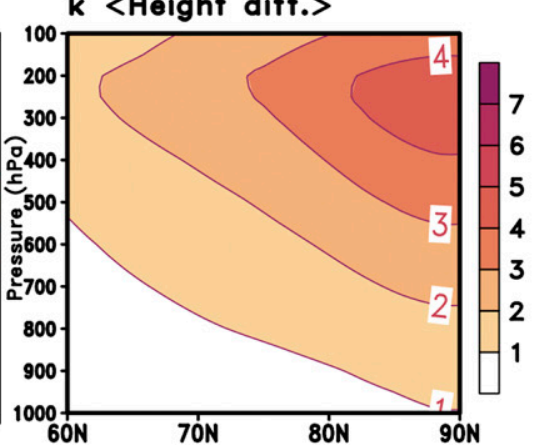

c RCP2.6 Temp. diff.

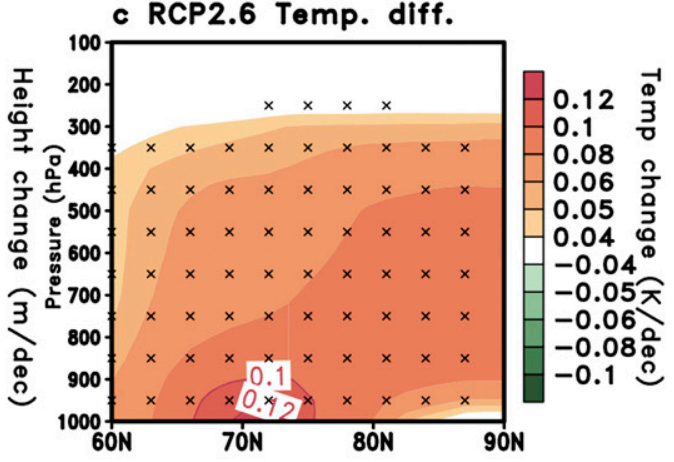

f RCP4.5 Temp. diff.

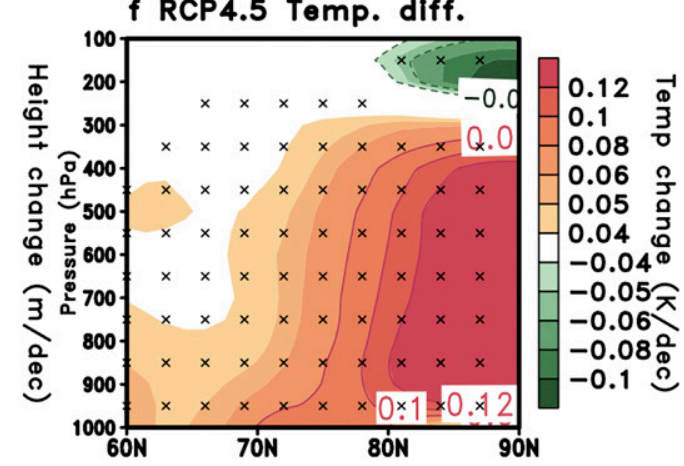

I RCP8.5 Temp. diff.
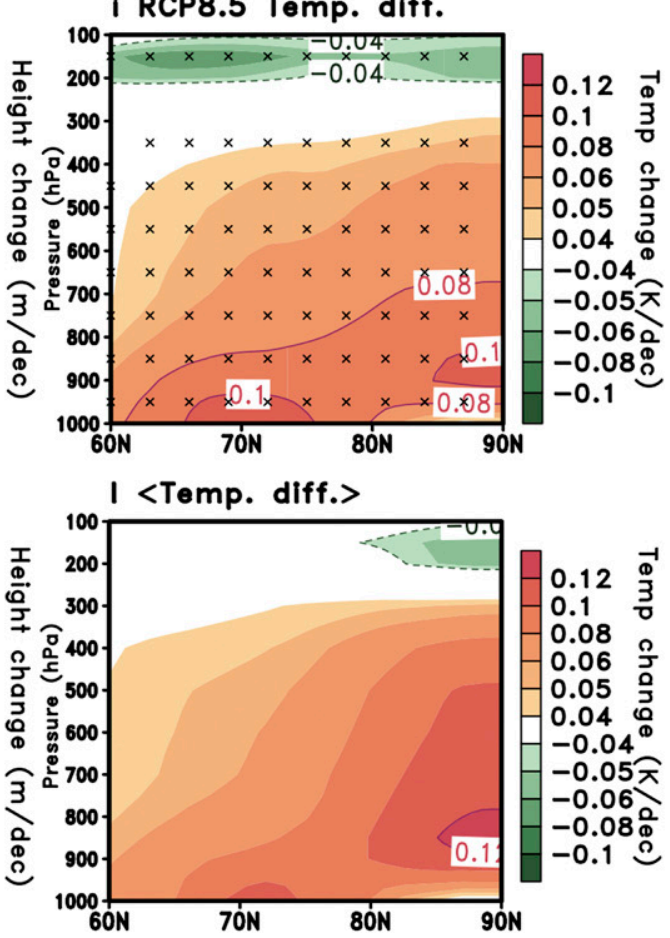

FIG. 10. Future fast-minus-slow composite trend plots of JJA (left) Z200, (center) zonal mean geopotential height, and (right) zonal mean temperature in (a)-(i) the three RCP scenarios of MPI-GE for 2020-50 and (j)-(l) the arithmetic mean of the composites belonging to each of the three scenarios. Crosses indicate significance on the $95 \%$ confidence level (two-sample $t$ test). 
So far, we have demonstrated strong, qualitative consensus between the observed and modeled circulationsea ice coupling pattern on both interannual and low-frequency time scales that is generated by internal variability in model simulations regardless of the differing external forcing scenarios or the model physics. However, we have also seen that all models tend to underestimate the magnitude of the atmosphere-sea ice coupling on year-to-year (Fig. 3), which presumably has impacts on the fast-minus-slow composite trend magnitudes. To gain a more detailed understanding of this discrepancy, we turn to analyzing remote drivers of this local coupling.

\section{Tropical drivers of local atmosphere-sea ice coupling}

\section{a. Observed connection between tropical JJA SST and September SIA}

In this section we attempt to assess what physical mechanism can possibly drive the atmospheric process revealed in the preindustrial, historical, and, more importantly, future model runs. Observations show significant negative convective heating anomalies over the east-central Pacific in summer during 1979-2012 resulting in a Rossby wave train-like atmospheric teleconnection pattern representing the leading internal mode connecting the Arctic to the tropics (Ding et al. 2014, 2019; Baxter et al. 2019). This propagating Rossby wave train has been attributed to part of the observed prominent geopotential height rise over Greenland between 2007 and 2012 causing rapid sea ice loss in addition to the anthropogenically forced melting (Baxter et al. 2019). Because of the observed modest but significant positive correlation $(\sim 0.5)$ between September SIA and tropical JJA SST and TS (Figs. 11a,b), we search for possible remote dynamical coupling between the summer tropical SST and the subsequent September sea ice conditions (Ding et al. 2014, 2017; Meehl et al. 2018; Baxter et al. 2019).

\section{b. The missing tropical-Arctic connection in the five large ensembles and CMIP5}

Figure 11 shows how September sea ice is statistically connected to the preceding summer tropical TS values by showing linear correlations in the five LE historical experiments (Figs. 11c-g). Correlations are first computed in each member of the given ensemble (after removing the ensemble mean from each member) and then averaged over the whole ensemble in each of the five single-model ensembles. Additionally, the correlation maps for the mean of the four LEs (Fig. 11h) and the mean of 31 CMIP5 unforced preindustrial simulations
(Fig. 12a) along with the individual CMIP5 models (Fig. 12b) and the individual ensemble members (Fig. 11i) are shown. We find that neither of the models share the observed significant positive correlations from the northeast-central Pacific $\left(0^{\circ}-25^{\circ} \mathrm{N} ; 180^{\circ}-115^{\circ} \mathrm{W}\right)$ on yearto-year time scales in either the historical LE or CMIP5 preindustrial runs. Only $3(<1 \%)$ of the $240(100+50+$ $40+30+20)$ LE members capture significant positive correlation, with none of them being as high as the observed one. Most important is that prevalent members of the LEs and of the CMIP5 multimodel ensemble show negative correlations indicating an opposite sign coupling relative to observations, with a warm-Pacific-warm-Arctic pattern instead of the observed cold-Pacific-warm-Arctic pattern.

The lack of a correctly replicated Pacific-Arctic connection motivates us to utilize the fast-minus-slow JJA Z200 and TS composites to trace back possible mechanisms that can lead to the formation of the Arctic anomalous high pressure seen in the composites in Figs. 5-10. We plot fast-minus-slow TS (shading) and Z200 (contours) composites in the Northern Hemisphere for the historical in Fig. 13 and for the future time frame in Fig. 14 to visualize internal variations in summertime TS and Z200 associated with September sea ice conditions.

As for the historical time frame, the models capture signals from the tropics connected to Arctic September sea ice variability; however, neither the sign nor the magnitude is reproduced compared to the observed TS and Z200 linear trends (Figs. 13a,b). Observations reveal a negative trend in the northeast-central Pacific surface temperatures for 1979-2012 resembling the negative phase of the IPO, while models do not show such pattern in either the fast-minus-slow or the forced trend components. The composites exhibit the opposite phase of the IPO in each of the simulations: a positive summer IPO pattern concomitant to sea ice retreat. The modeled atmospheric teleconnection pattern seems to behave as a stationary wave superimposed onto the zonal mean flow with the warm phase in the tropical Pacific, instead of mirroring the observed Rossby wave train (Ding et al. 2014; Baxter et al. 2019) with negative phase in the tropics.

Further details of the simulated atmospheric teleconnection are revealed via the future composite plots in Fig. 14. Models stick to simulating a positive-IPO-like pattern in their future composites with warm TS anomalies in the east-central Pacific and cold anomalies in the northwest-central Pacific. The CESM-LE and the GFDL-LE exhibit more widespread, while the MPI-GE a dampened warming signal in the tropical Pacific compared to the historical period (Figs. 13, 14). However, no clear signal is observed from the tropical Atlantic, except for the CanESM-LE, which exhibits widespread cooling 
a JJA ERA-I TS vs. Sep SIA

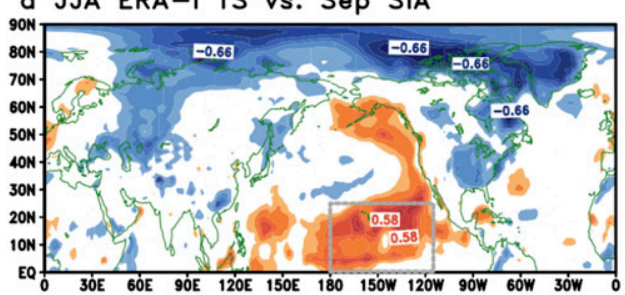

c MPI-GE JJA TS vs. Sep SIA

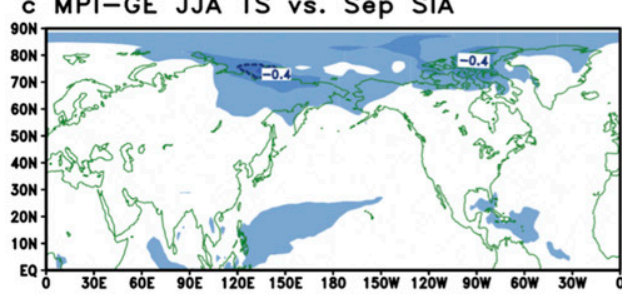

e CESM-LE JJA TS vs. Sep SIA

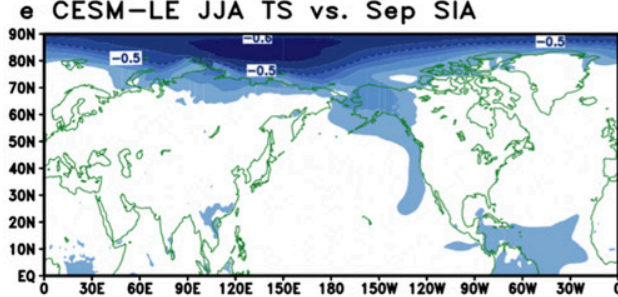

g GFDL-LE JJA TS vs. Sep SIA

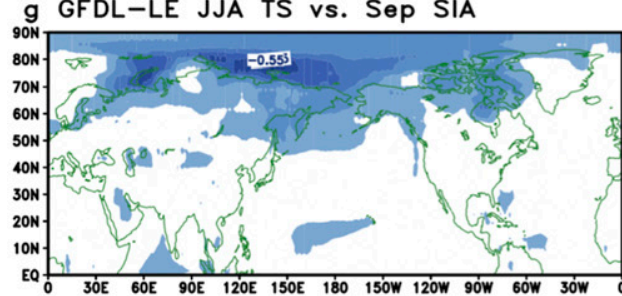

b JJA ERSSTV5 vs. Sep SIA

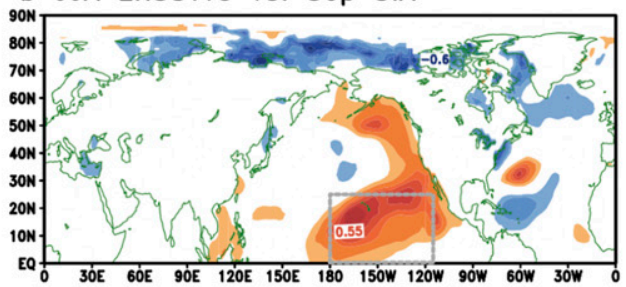

d CanESM-LE JJA TS vs. Sep SIA

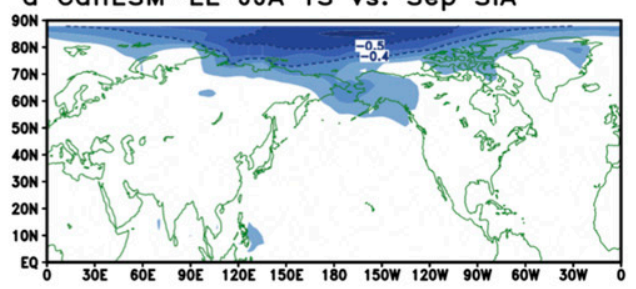

$f$ CSIRO-LE JJA TS vs. Sep SIA

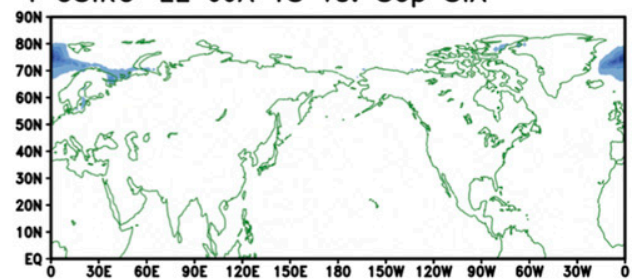

$h<4$ LE $>$ JJA TS vs. Sep SIA

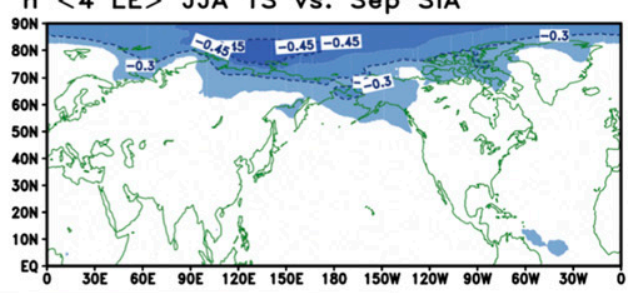

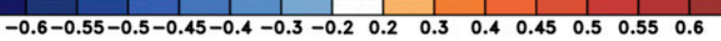

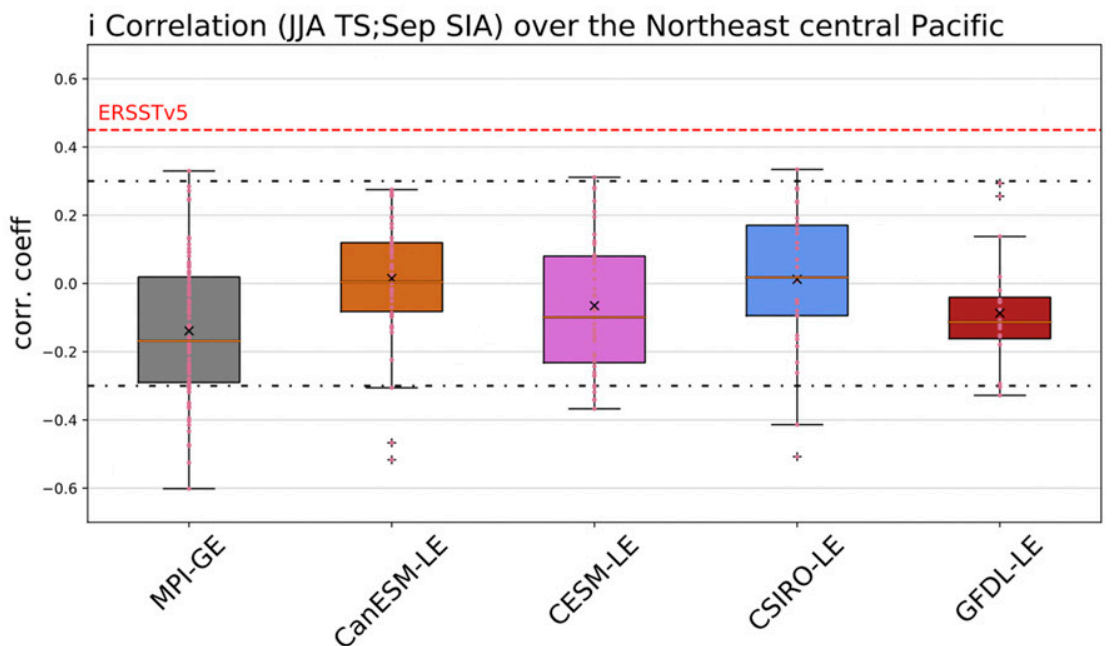

FIG. 11. Observed correlation of (a) linearly detrended JJA surface temperature (TS) and (b) linearly detrended JJA sea surface temperature (SST: ERSSTv5) with detrended September SIA index for 19792012. Also shown is the single-model LE average correlation between JJA TS and September SIA index for 1979-2012 in the five single-model large ensemble experiments (c) MPI-GE, (d) CanESM-LE, (e) CESMLE, (f) CSIRO-LE, and (g) GFDL-LE and (h) the average of 4 LEs (excluding CSIRO-LE). The forced 
in both the tropical and midlatitude Atlantic. Clearly, models disagree on specific details on how midlatitude or even tropical TS changes are associated with future sea ice loss.

Overall, the mismatch of the observed remote drivers of summertime sea ice variability warns us that current model dynamics may miss some important physical linkages connecting the Arctic to the lower latitudes. In addition, a recent study by Bonan and BlanchardWrigglesworth (2020) suggested that the observed Pacific-Arctic teleconnection may not be stable on longer time scales. Thus, we propose further research toward the application of paleoclimate proxy records in the tropics and the Arctic to shed more light on tropicalArctic dynamical linkages, which might be a promising candidate for a more reliable decadal-scale sea ice prediction.

\section{Discussion and conclusions}

In this paper, through an analysis of five large ensemble and dozens of long preindustrial simulations with a focus on simulated internal atmospheric variability, we have (i) evaluated current climate models' ability to replicate the dynamical processes partially responsible for the observed sea ice loss and its local and remote atmospheric drivers, and (ii) showed evidence for the importance of atmospheric drivers of future sea ice loss. The primary atmosphere-sea ice coupling mechanism is based on a series of model experiments in Ding et al. (2017) and is understood as a circulationdriven process that warms and moistens the lower troposphere adiabatically, thus regulating longwave radiation that causes sea ice melt. In this paper further evidence is presented that the same mechanism also represents the dominant internal atmospheric process in models that creates favorable conditions for sea ice melting on both the historical and future time frames, and this is regardless of differences in model physics. We have also seen that the atmosphere-sea ice coupling manifests in a somewhat different structure with external forcing at different intensities, thus, further research is advocated. Moreover, since models fail to fully replicate the observed intensity and sensitivity of the coupling between local and remote circulation changes with sea ice, the quantitative estimation to what extent the identified internal circulation variability can enhance the effect of anthropogenic forcing on the observed sea ice loss, along with the role of Pacific Ocean variability in decadal sea ice predictions remain uncertain.

One source of uncertainty is due to the limitation of the models in capturing the observed magnitude of the local atmosphere-sea ice coupling pattern (Fig. 3). Because of the similarities between the atmosphere-sea ice interactions seen on year-to-year and low-frequency time scales, it is reasonable to assume that the underestimated year-to-year coupling has an impact on the low-frequency focused composite calculations as well, likely contributing to the consistently weak magnitudes captured in the fast-minus-slow composites. Model limitations in simulating wind-driven mechanisms or moisture and cloud variability could be sources of biases in replicating the observed atmosphere-sea ice coupling (Hofer et al. 2019; Huang et al. 2019).

Another source of uncertainty regarding decadal sea ice simulation is model limitations in capturing the observed teleconnection originating from the tropical Pacific. In light of our results, recent findings of Screen and Deser (2019) involving the use of simulated IPO phase changes as a predictor of seasonal sea ice conditions might be suspect given that current LEs' historical simulations fail to capture the correct sign of the observed Pacific decadal TS trends. This casts a shadow over models' credibility in simulating future changes in the tropical Pacific that could be used for Arctic sea ice projections. Suggestions for the importance of summer Atlantic tropical SST in driving sea ice variability (Meehl et al. 2018; Castruccio et al. 2019; McCrystall et al. 2020) seems to be at odds with our findings: in our Z200/TS composite plots, no common features are observable across the models in the tropical Atlantic regions (Figs. 13, 14). We advocate future efforts dedicated to elucidating the relative contribution of tropical Atlantic and Pacific SST variability along with untangling which

\footnotetext{
$\leftarrow$

component (ensemble mean) is removed from each member before calculating correlations. Correlation is first computed in each member, then averaged over the whole ensemble for each of (c) $-(\mathrm{g})$. (i) Correlation in all members of the five LEs (indicated below the $x$ axis) between detrended northeast-central Pacific area-averaged $\left[0^{\circ}-25^{\circ} \mathrm{N} ; 180^{\circ}-115^{\circ} \mathrm{W}\right.$, indicated with the gray-outlined box in (a) and (b)] JJA TS and September SIA index for 1979-2012. The whiskers extend to 1.5 × IQR. Crosses mark average values; plus signs mark the outliers (outside $1.5 \times \mathrm{IQR}$ ). The median is indicated with an orange horizontal line. The horizontal dashed red line marks the observed correlation; the black dotted lines mark the significance (based on Student's $t$ test 95\% confidence interval).
} 
a 31 CMIP5 control JJA TS vs. Sep SIA
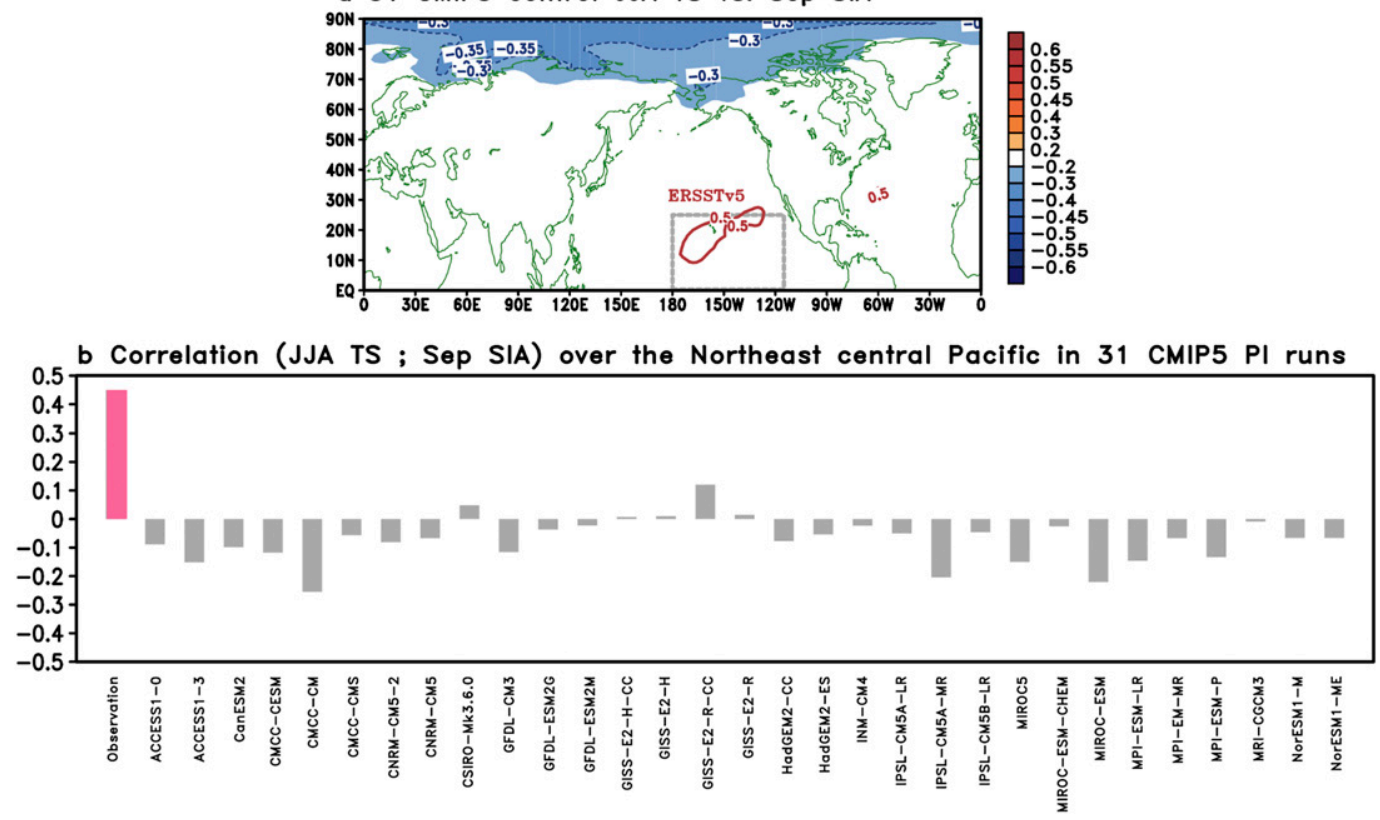

FIG. 12. (a) 31-member multimodel ensemble average correlation of JJA TS with September total SIA index from the CMIP5 long preindustrial (PI) control runs (blue shading and contour) and observed correlation of JJA SST (ERSSTv5) with September total SIA index for 1979-2012 (red contour). The correlation map for each CMIP5 model is calculated separately over the entire integration period (see Table 1), and then the 31 correlation patterns are averaged to construct a 31-member multimodel ensemble average. All variables are linearly detrended before correlation. (b) Correlation between linearly detrended September total SIA index and linearly detrended northeast-central Pacific area-averaged $\left[0^{\circ}-25^{\circ} \mathrm{N} ; 180^{\circ}-115^{\circ} \mathrm{W}\right.$, indicated with the gray-outlined box in (a)] TS in observations $(r=0.45$, with $p<0.05$; pink bar) and in each of the 31 individual CMIP5 multimodel ensemble members' PI runs (gray bars).

side of the tropical Pacific basin has more prominence in driving Arctic sea ice variability (Dong et al. 2019; Warner et al. 2020).

We also note that in models the local Arctic atmosphere-sea ice coupling still exists without prominent remote tropical forcing although the magnitude of the coupling is weaker. This indicates that the generation of the local coupling could also be due to local feedback. Further research toward identifying the relative role of the local and remote forcing mechanisms in the observed atmosphere-sea ice interactions is needed.

Although a recent study by Olonscheck et al. (2019) also emphasized that atmospheric processes dominate Arctic sea ice variability, we cannot rule out the role of the heat content change in the ocean (Steele et al. 2008, 2010; Zhang et al. 2013; Deser et al. 2015). Limitations of our methodology can also leave undetected variability belonging to either atmospheric or oceanic processes, since the fast-minus-slow method relies on a subjective choice of ensemble members belonging to the fast and slow groups. However, applying our linear method to the pseudoensemble of preindustrial control simulations, we also showed an example of how long control runs may be utilized to evaluate model performance. We are also aware that there is no guarantee that the strength of the teleconnections remains constant in the future under high emission scenarios (Herein et al. 2016, 2017; Tél et al. 2020; Haszpra et al. 2020); therefore nonlinear, higher-order processes may also play a significant role.

Our study reveals that current climate model simulations are able to replicate the physical mechanism of the observed atmosphere-sea ice coupling in preindustrial, historical, and future model simulations, emphasizing the importance of internal atmospheric variability in driving present and future sea ice melting. The present analysis, however, is solely focused on reaching a qualitative understanding of internal drivers of sea ice loss across different model environments; thus, the relative contribution of internal variability remains an open question in light of limited model performance. Overall, we argue that more effort should be given to model development to correctly replicate these physical linkages in our observed climate system. Phase 6 of the Coupled Model Intercomparison Project (CMIP6) with updated model versions potentially will improve the presented uncertainties, and, if so, CMIP6 simulations 

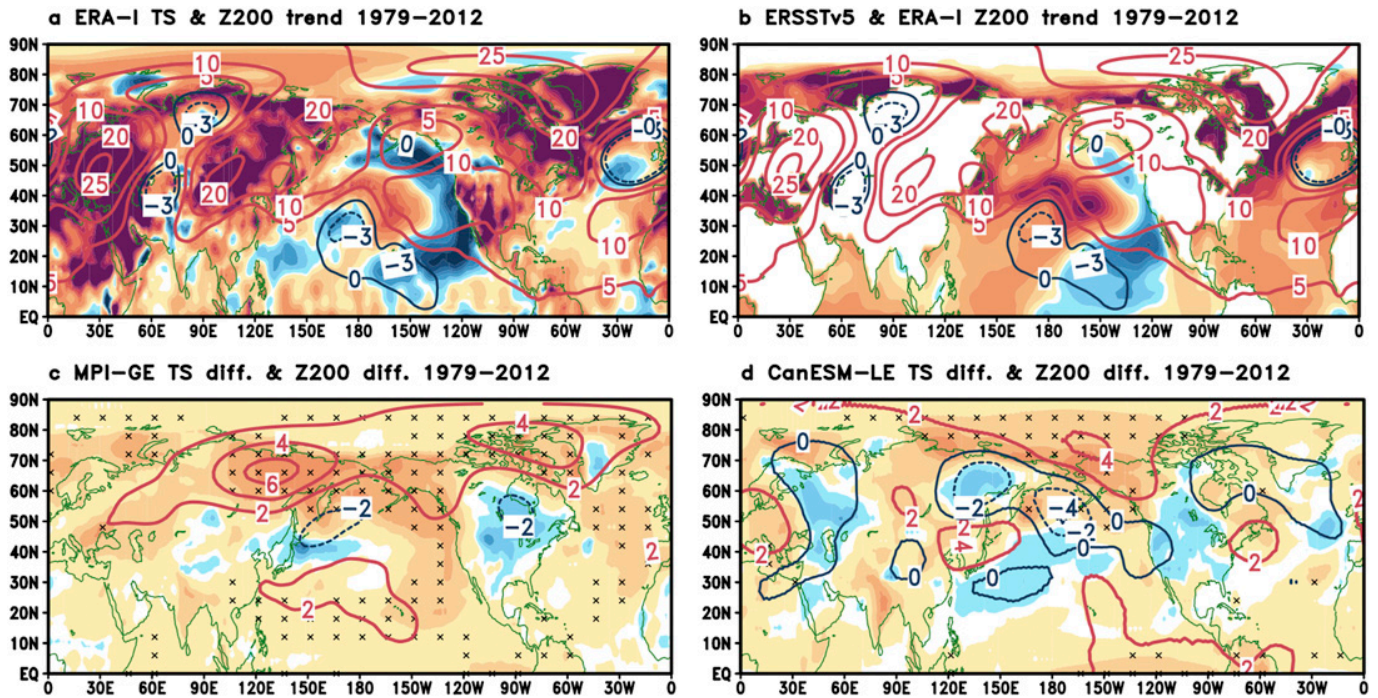

- CESM-LE TS diff. \& Z200 diff. 1979-2012

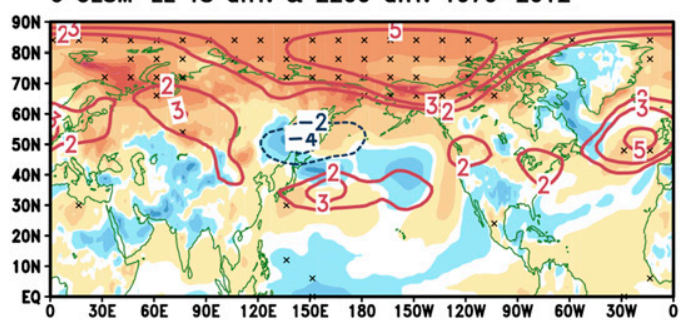

f CSIRO-LE TS diff. \& Z200 diff. 1979-2012
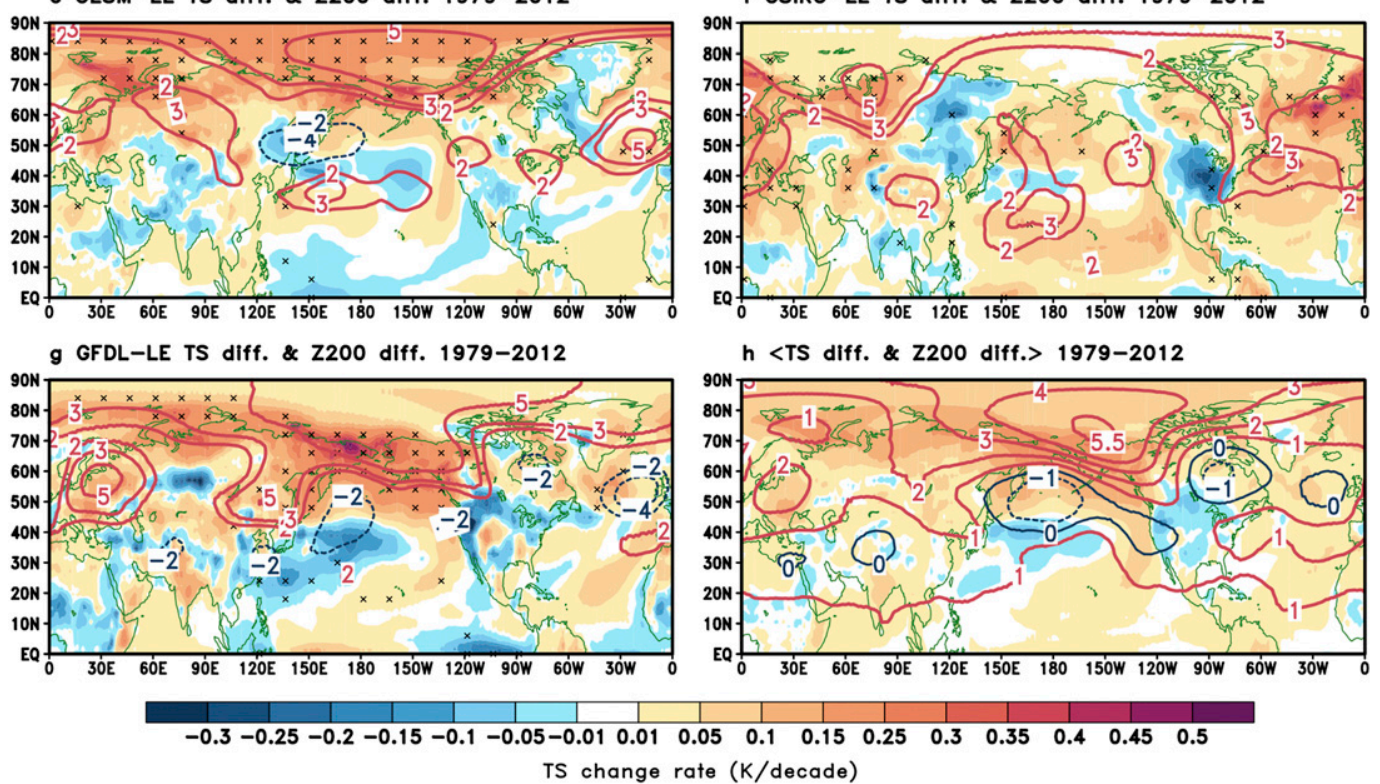

FIG. 13. Linear trends of JJA Z200 (contours) and (a) TS (ERA-I; shading) or (b) SST (ERSSTv5; shading) for 1979-2012 in observations. Also shown are historical fast-minus-slow composite trends of JJA Z200 (contours) and TS (shading) in the five LEs' historical + RCP8.5 simulations for 1979-2012: (c) MPI-GE, (d) CanESM-LE, (e) CESM-LE, (f) CSIRO-LE, (g) GFDL-LE, and (h) the average of four LE (excluding CSIRO-LE; denoted with angle brackets). Crosses indicate significant TS composite values on the $95 \%$ level (two-sample $t$ test).

may be promising sources of improved decadal-scale sea ice predictability.

Acknowledgments. We acknowledge constructive comments from three anonymous reviewers and the editor, Prof. James Screen, all of which have led to considerable improvements in the paper. This study was supported by the National Science Foundation's Polar
Programs (OPP-1744598); Modeling, Analysis, Predictions and Projections (NA19OAR4310281); and Ocean Observing and Monitoring (NA18OAR4310424) programs as part of NOAA's Climate Program Office. Author Topál is supported by the ÚNKP-19-3 New National Excellence Program of the Ministry for Innovation and Technology and Grant NTP-NFTÖ-18 of the Ministry of Human Capacities. The paper was also supported by 
a MPI-GE TS diff. \& Z200 diff. 2020-2050

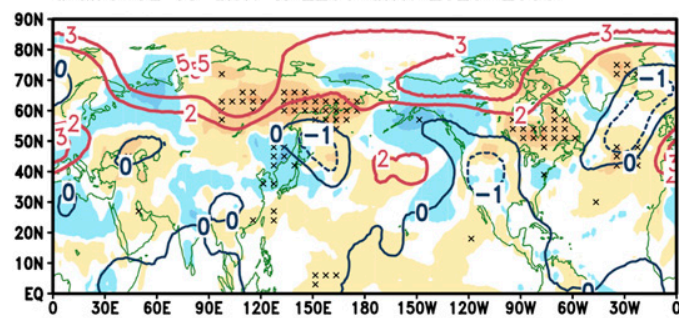

c CESM-LE diff. \& Z200 diff. 2020-2050

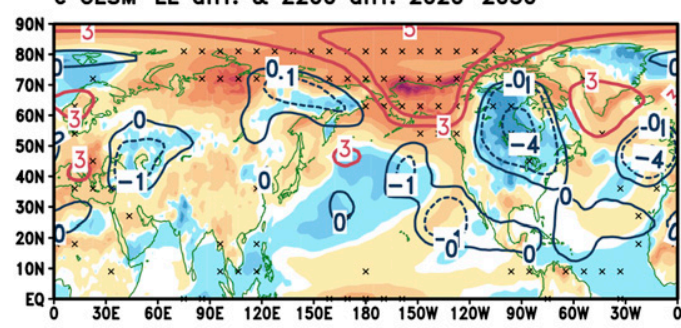

e GFDL-LE TS diff. \& Z200 diff. 2020-2050

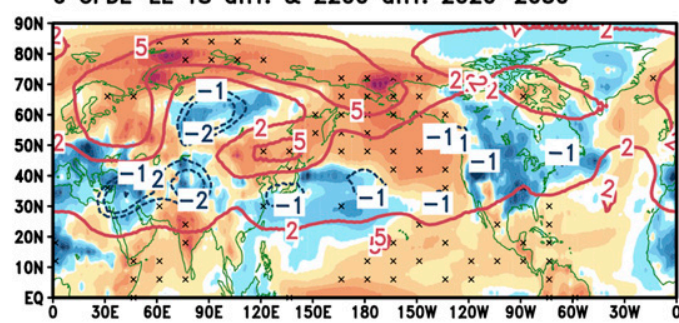

b CanESM-LE TS diff. \& Z200 diff. 2020-2050

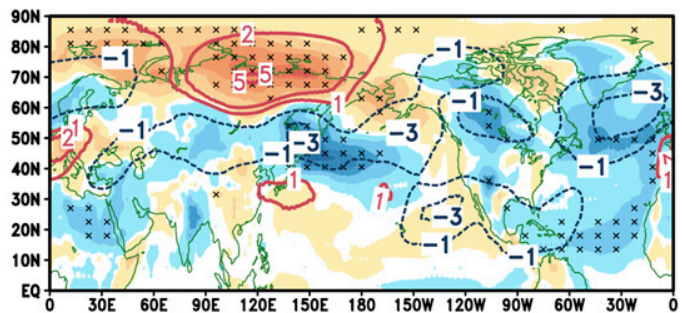

d CSIRO-LE TS diff. \& Z200 diff. 2020-2050

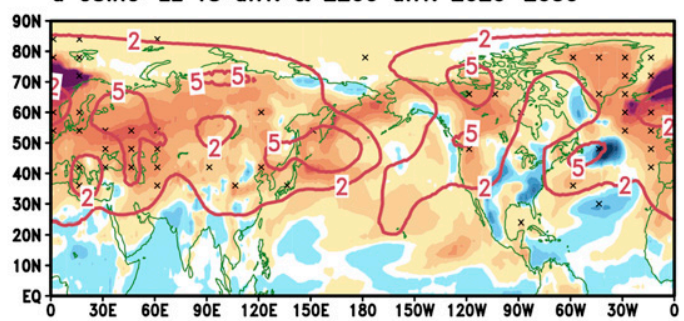

$f<$ TS diff. \& Z200 diff.> 2020-2050

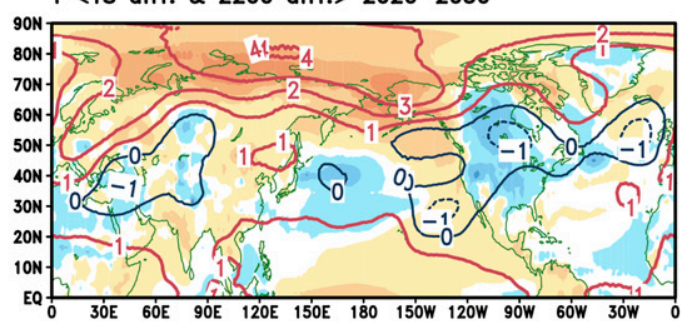

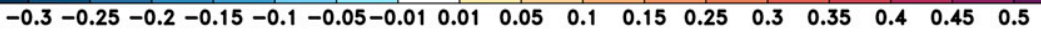

TS change rate $(\mathrm{K} /$ decade)

FIG. 14. Future fast-minus-slow composite trends of JJA Z200 (contours) and TS (shading) in the five LEs' RCP8.5 simulations for 2020-50: (a) MPI-GE, (b) CanESM-LE, (c) CESM-LE, (d) CSIRO-LE, (e) GFDL-LE, and (f) the average of four LE (excluding CSIRO-LE). Crosses indicate significant TS composite values on the $95 \%$ level (two-sample $t$ test).

the ÚNKP-18-4 New National Excellence Program of the Ministry of Innovation and Technology (author Haszpra); by the János Bolyai Research Scholarship of the Hungarian Academy of Sciences (Haszpra); and by the National Research, Development and Innovation Office-NKFIH under Grants PD-121305 (Haszpra), PD124272 (author Herein), FK-124256 (Haszpra, Herein, and Topál), and K-125171 (Haszpra and Herein). Author Li is supported by the National Natural Science Foundation of China (Grant 41790471) and the Strategic Priority Research Program of Chinese Academy of Sciences (Grant XDA20100304). We thank Gábor Drótos for insightful discussion and hints on the intermember MCA analysis. We acknowledge the U.S. CLIVAR Large Ensemble Working Group. Author Topál is further grateful for the support from Dr. László Sólyom and the Saint Ignatius Jesuit Collage for Advanced Studies.

\section{REFERENCES}

Baxter, I., and Coauthors, 2019: How tropical Pacific surface cooling contributed to accelerated sea ice melt from 2007 to 2012 as ice is thinned by anthropogenic forcing. J. Climate, $\mathbf{3 2}$, 8583-8602, https://doi.org/10.1175/JCLI-D-18-0783.1.

Blanchard-Wrigglesworth, E., and Q. Ding, 2019: Tropical and midlatitude impact on seasonal polar predictability in the Community Earth System Model. J. Climate, 32, 5997-6014, https://doi.org/10.1175/JCLI-D-19-0088.1.

Bonan, D. B., and E. Blanchard-Wrigglesworth, 2020: Nonstationary teleconnection between the Pacific Ocean and Arctic sea ice. Geophys. Res. Lett., 47, e2019GL085666, https://doi.org/10.1029/ 2019GL085666.

Bretherton, C. S., C. Smith, and J. M. Wallace, 1992: An intercomparison of methods for finding coupled patterns in climate data. J. Climate, 5, 541-560, https://doi.org/10.1175/1520-0442(1992) 005<0541:AIOMFF>2.0.CO;2.

Castruccio, F. S., Y. Ruprich-Robert, S. G. Yeager, G. Danabasoglu, R. Msadek, and T. L. Delworth, 2019: Modulation of Arctic sea ice loss by atmospheric teleconnections from Atlantic 
multidecadal variability. J. Climate, 32, 1419-1441, https:// doi.org/10.1175/JCLI-D-18-0307.1.

Cavalieri, D. J., C. L. Parkinson, P. Gloersen, and H. J. Zwally, 1996: Sea ice concentrations from Nimbus-7 SMMR and DMSP SSM/I-SSMIS passive microwave data, version 1. Subset used: V3-NH, NASA, National Snow and Ice Data Center Distributed Active Archive Center, accessed 29 April 2018, https://doi.org/10.5067/8GQ8LZQVL0VL.

Chylek, P., C. K. Folland, G. Lesins, M. K. Dubey, and M. Wang, 2009: Arctic air temperature change amplification and the Atlantic multidecadal oscillation. Geophys. Res. Lett., 36, L14801, https://doi.org/10.1029/2009GL038777.

Cohen, J., and Coauthors, 2014: Recent Arctic amplification and extreme mid-latitude weather. Nat. Geosci., 7, 627-637, https:// doi.org/10.1038/ngeo2234.

Day, J. J., J. C. Hargreaves, J. D. Annan, and A. Abe-Ouchi, 2012: Sources of multi-decadal variability in Arctic sea ice extent. Environ. Res. Lett., 7, 034011, https://doi.org/10.1088/17489326/7/3/034011.

Dee, D. P., and Coauthors, 2011: The ERA-Interim reanalysis: Configuration and performance of the data assimilation system. Quart. J. Roy. Meteor. Soc., 137, 553-597, https://doi.org/ 10.1002/qj.828.

Deser, C., R. Tomas, M. Alexander, and D. Lawrence, 2010: The seasonal atmospheric response to projected Arctic sea ice loss in the late twenty-first century. J. Climate, 23, 333-351, https:// doi.org/10.1175/2009JCLI3053.1.

-,- , and L. Sun, 2015: The role of ocean-atmosphere coupling in the zonal-mean atmospheric response to Arctic sea ice loss. J. Climate, 28, 2168-2186, https://doi.org/10.1175/JCLID-14-00325.1.

— , and Coauthors, 2020: Insights from Earth system model initial-condition large ensembles and future prospects. Nat. Climate Change, 10, 277-286, https://doi.org/10.1038/s41558020-0731-2.

Ding, Q., J. M. Wallace, D. S. Battisti, E. J. Steig, A. J. Gallant, H. J. Kim, and L. Geng, 2014: Tropical forcing of the recent rapid Arctic warming in northeastern Canada and Greenland. Nature, 509, 209-212, https://doi.org/10.1038/nature13260.

_ _ and Coauthors, 2017: Influence of high-latitude atmospheric circulation changes on summertime Arctic sea ice. Nat. Climate Change, 7, 289-295, https://doi.org/10.1038/nclimate3241.

— , and Coauthors, 2019: Fingerprints of internal drivers of Arctic sea ice loss in observations and model simulations. Nat. Geosci., 12, 28-33, https://doi.org/10.1038/s41561-018-0256-8.

Dong, Y., C. Proistosescu, K. C. Armour, and D. S. Battisti, 2019: Attributing historical and future evolution of radiative feedbacks to regional warming patterns using a Green's function approach: The preeminence of the western Pacific. J. Climate, 32, 5471-5491, https://doi.org/10.1175/JCLI-D-18-0843.1.

Drótos, G., T. Bódai, and T. Tél, 2015: Probabilistic concepts in a changing climate: A snapshot attractor picture. J. Climate, 28, 3275-3288, https://doi.org/10.1175/JCLI-D-14-00459.1.

England, M., A. Jahn, and L. Polvani, 2019: Nonuniform contribution of internal variability to recent Arctic sea ice loss. J. Climate, 32, 4039-4053, https://doi.org/10.1175/JCLI-D-18-0864.1.

Grunseich, G., and B. Wang, 2016: Arctic sea ice patterns driven by the Asian summer monsoon. J. Climate, 29, 9097-9112, https:// doi.org/10.1175/JCLI-D-16-0207.1.

Hahn, L., C. C. Ummenhofer, and Y.-O. Kwon, 2018: North Atlantic natural variability modulates emergence of widespread Greenland melt in a warming climate. Geophys. Res. Lett., 45, 9171-9178, https://doi.org/10.1029/2018GL079682.
Haszpra, T., D. Topál, and M. Herein, 2020: On the time evolution of the Arctic oscillation and related wintertime phenomena under different forcing scenarios in an ensemble approach. J. Climate, 33, 3107-3124, https://doi.org/10.1175/JCLI-D-190004.1.

Herein, M., J. Márfy, G. Drótos, and T. Tél, 2016: Probabilistic concepts in intermediate-complexity climate models: A snapshot attractor picture. J. Climate, 29, 259-272, https://doi.org/ 10.1175/JCLI-D-15-0353.1.

— G. Drótos, T. Haszpra, J. Márfy, and T. Tél, 2017: The theory of parallel climate realizations as a new framework for teleconnection analysis. Sci. Rep., 7, 44529, https://doi.org/10.1038/ srep44529.

Hofer, S., A. J. Tedstone, X. Fettweis, and J. L. Bamber, 2019: Cloud microphysics and circulation anomalies control differences in future Greenland melt. Nat. Climate Change, 9, 523528, https://doi.org/10.1038/s41558-019-0507-8.

Huang, B., and Coauthors, 2017: NOAA Extended Reconstructed Sea Surface Temperature (ERSST), version 5 [global]. NOAA National Centers for Environmental Information, accessed 12 December 2018, https://doi.org/10.7289/V5T72FNM.

Huang, Y., and Coauthors, 2019: Thicker clouds and accelerated Arctic Sea ice decline: The atmosphere-sea ice interactions in spring. Geophys. Res. Lett., 46, 6980-6989, https://doi.org/ 10.1029/2019GL082791.

Jahn, A., 2018: Reduced probability of ice-free summers for $1.5^{\circ} \mathrm{C}$ compared to $2^{\circ} \mathrm{C}$ warming. Nat. Climate Change, 8, 409-413, https://doi.org/10.1038/s41558-018-0127-8.

Jeffrey, S., L. Rotstayn, M. Collier, S. Dravitzki, C. Hamalainen, C. Moeseneder, K. Wong, and J. Skytus, 2013: Australia's CMIP5 submission using the CSIRO-Mk3.6 model. Aust. Meteor. Oceanogr. J., 63, 1-14, https://doi.org/10.22499/2.6301.001.

Kay, J. E., and Coauthors, 2015: The Community Earth System Model (CESM) large ensemble project: A community resource for studying climate change in the presence of internal climate variability. Bull. Amer. Meteor. Soc., 96, 1333-1349, https://doi.org/10.1175/BAMS-D-13-00255.1.

Kirchmeier-Young, M. C., F. W. Zwiers, and N. P. Gillett, 2017: Attribution of extreme events in Arctic sea ice extent. J. Climate, 30, 553-571, https://doi.org/10.1175/JCLI-D-16-0412.1.

Labe, Z., Y. Peings, and G. Magnusdottir, 2019: The effect of QBO phase on the atmospheric response to projected Arctic sea ice loss in early winter. Geophys. Res. Lett., 46, 7663-7671, https:// doi.org/10.1029/2019GL083095.

Lee, S., 2012: Testing of the tropically excited Arctic warming mechanism (TEAM) with traditional El Niño and La Niña. J. Climate, 25, 4015-4022, https://doi.org/10.1175/JCLI-D-1200055.1.

Li, G., S.-P. Xie, C. He, and Z. Chen, 2017: Western Pacific emergent constraint lowers projected increase in Indian summer monsoon rainfall. Nat. Climate Change, 7, 708-712, https://doi.org/10.1038/nclimate3387.

Maher, N., and Coauthors, 2019: The Max Planck Institute Grand Ensemble-Enabling the exploration of climate system variability. J. Adv. Model. Earth Syst., 11, 2050-2069, https:// doi.org/10.1029/2019MS001639.

McCrystall, M. R., J. S. Hosking, I. P. White, and A. C. Maycock, 2020: The impact of changes in tropical sea surface temperatures over 1979-2012 on Northern Hemisphere high-latitude climate. J. Climate, 33, 5103-5121, https://doi.org/10.1175/ JCLI-D-19-0456.1.

Meehl, G. A., C. T. Y. Chung, J. M. Arblaster, M. M. Holland, and C. M. Bitz, 2018: Tropical decadal variability and the rate of 
Arctic sea ice decrease. Geophys. Res. Lett., 45, 11 326-11333, https://doi.org/10.1029/2018GL079989.

Mioduszewski, J. R., A. K. Rennermalm, A. Hammann, M. Tedesco, E. U. Noble, J. C. Stroeve, and T. L. Mote, 2016: Atmospheric drivers of Greenland surface melt revealed by self-organizing maps. J. Geophys. Res. Atmos., 121, 5095-5114, https://doi.org/ 10.1002/2015JD024550.

Notz, D., 2014: Sea-ice extent and its trend provide limited metrics of model performance. Cryosphere, $\mathbf{8}, 229-243$, https://doi.org/ 10.5194/tc-8-229-2014.

, and J. Marotzke, 2012: Observations reveal external driver for Arctic sea-ice retreat. Geophys. Res. Lett., 39, L08502, https://doi.org/10.1029/2012GL051094.

-, and J. Stroeve, 2016: Observed Arctic sea ice loss directly follows anthropogenic $\mathrm{CO}_{2}$ emission. Science, 354, 747-750, https://doi.org/10.1126/science.aag2345.

—, A. Haumann, H. Haak, J. Jungclaus, and J. Marotzke, 2013: Arctic sea ice evolution as modeled by Max Planck Institute for Meteorology's Earth system model. J. Adv. Model. Earth Syst., 5, 173-194, https://doi.org/10.1002/jame.20016.

Olonscheck, D., T. Mauritsen, and D. Notz, 2019: Arctic sea-ice variability is primarily driven by atmospheric temperature fluctuations. Nat. Geosci., 12, 430-434, https://doi.org/10.1038/ s41561-019-0363-1.

Rosenblum, E., and I. Eisenman, 2017: Sea ice trends in climate models only accurate in runs with biased global warming. J. Climate, $\mathbf{3 0}$, 6265-6278, https://doi.org/10.1175/JCLI-D-16-0455.1.

Screen, J. A., and I. Simmonds, 2010: The central role of diminishing sea ice in recent Arctic temperature amplification. Nature, 464, 1334-1337, https://doi.org/10.1038/nature09051.

— , and J. A. Francis, 2016: Contribution of sea ice loss to Arctic amplification is regulated by Pacific Ocean decadal variability. Nat. Climate Change, 6, 856-860, https://doi.org/10.1038/nclimate3011.

— time of emergence of a seasonally ice-free Arctic Ocean. Geophys. Res. Lett., 46, 2222-2231, https://doi.org/10.1029/ 2018 GL081393.

- - and Coauthors, 2018: Consistency and discrepancy in the atmospheric response to Arctic sea-ice loss across climate models. Nat. Geosci., 11, 155-163, https://doi.org/10.1038/ s41561-018-0059-y.

SIMIP Community, 2020: Arctic sea ice in CMIP6. Geophys. Res. Lett., 47, e2019GL086749, https://doi.org/10.1029/2019GL086749.

Simmonds, I., 2015: Comparing and contrasting the behaviour of Arctic and Antarctic sea ice over the 35 year period 1979-2013. Ann. Glaciol., 56, 18-28, https://doi.org/10.3189/2015AoG69A909.

Steele, M., W. Ermold, and J. Zhang, 2008: Arctic Ocean surface warming trends over the past 100 years. Geophys. Res. Lett., 35, L02614, https://doi.org/10.1029/2007GL031651.

_ J. Zhang, and W. Ermold, 2010: Mechanisms of summertime upper Arctic Ocean warming and the effect on sea ice melt. J. Geophys. Res., 115, C11004, https://doi.org/10.1029/2009JC005849.

Sun, L., M. Alexander, and C. Deser, 2018: Evolution of the global coupled climate response to Arctic sea ice loss during 1990-2090 and its contribution to climate change. J. Climate, 31, 7823-7843, https://doi.org/10.1175/JCLI-D-18-0134.1.
Svendsen, L., N. Keenlyside, I. Bethke, Y. Gao, and N.-E. Omrani, 2018: Pacific contribution to the early twentieth-century warming in the Arctic. Nat. Climate Change, 8, 793-797, https://doi.org/10.1038/s41558-018-0247-1.

Swart, N. C., J. C. Fyfe, E. Hawkins, J. E. Kay, and A. Jahn, 2015: Influence of internal variability on Arctic sea ice trends. Nat. Climate Change, 5, 86-89, https://doi.org/10.1038/nclimate2483.

Taylor, K. E., R. J. Stouffer, and G. A. Meehl, 2012: An overview of CMIP5 and the experiment design. Bull. Amer. Meteor. Soc., 93, 485-498, https://doi.org/10.1175/BAMS-D-11-00094.1.

Tél, T., T. Bódai, G. Drótos, T. Haszpra, M. Herein, B. Kaszás, and M. Vincze, 2020: The theory of parallel climate realizations. J. Stat. Phys., https://doi.org/10.1007/s10955-019-02445-7, in press.

Tokinaga, H., S. P. Xie, and H. Mukougawa, 2017: Early 20thcentury Arctic warming intensified by Pacific and Atlantic multidecadal variability. Proc. Natl. Acad. Sci. USA, 114, 6227-6232, https://doi.org/10.1073/pnas.1615880114.

Uotila, P., S. O'Farrell, S. J. Marsland, and D. Bi, 2013: The sea-ice performance of the Australian climate models participating in the CMIP5. Aust. Meteor. Oceanogr. J., 63, 121-143, https:// doi.org/10.22499/2.6301.008.

Vaughan, D. G., and Coauthors, 2013: Observations: Cryosphere. Climate Change 2013: The Physical Science Basis, T. F. Stocker et al., Eds., Cambridge University Press, 317-382.

Warner, J. L., J. A. Screen, and A. A. Scaife, 2020: Links between Barents-Kara sea ice and the extratropical atmospheric circulation explained by internal variability and tropical forcing. Geophys. Res. Lett., 47, e2019GL085679, https://doi.org/ 10.1029/2019GL085679.

Wernli, H., and L. Papritz, 2018: Role of polar anticyclones and mid-latitude cyclones for Arctic summertime sea ice melting. Nat. Geosci., 11, 108-113, https://doi.org/10.1038/s41561-0170041-0.

Winton, M., 2011: Do climate models underestimate the sensitivity of Northern Hemisphere sea ice cover? J. Climate, 24, 39243934, https://doi.org/10.1175/2011JCLI4146.1.

Ye, K., and T. Jung, 2019: How strong is influence of the tropics and midlatitudes on the Arctic atmospheric circulation and climate change? Geophys. Res. Lett., 46, 4942-4952, https:// doi.org/10.1029/2019GL082391.

Zelinka, M. D., T. A. Myers, D. T. McCoy, S. Po-Chedley, P. M. Caldwell, P. Ceppi, and K. E. Taylor, 2020: Causes of higher climate sensitivity in CMIP6 models. Geophys. Res. Lett., 47, e2019GL085782, https://doi.org/10.1029/2019GL085782.

Zhang, J., R. Lindsay, A. Schweiger, and M. Steele, 2013: The impact of an intense summer cyclone on 2012 Arctic sea ice retreat. Geophys. Res. Lett., 40, 720-726, https://doi.org/ 10.1002/grl.50190.

Zhang, R., 2007: Anticorrelated multidecadal variations between surface and subsurface tropical North Atlantic. Geophys. Res. Lett., 34, L12713, https://doi.org/10.1029/2007GL030225. , 2015: Mechanisms fo,r low-frequency variability of summer Arctic sea ice extent. Proc. Natl. Acad. Sci. USA, 112, 45704575, https://doi.org/10.1073/pnas.1422296112. 